\title{
A vida com molibdénio
}

\author{
Luisa B. Maia(a) e José J. G. Moura \\ LAQV, REQUIMTE, FCT NOVA, Portugal \\ luisa.maia@fct.unl.pt; jose.moura@fct.unl.pt
}

\begin{abstract}
Life with molybdenum - The year of 2019 was declared by UNESCO as the "International Year of the Periodic Table of Chemical Elements", celebrating the 150th anniversary of its creation by the Russian scientist Dmitry Mendeleev. We took this opportunity to bring to light one chemical element whose relevance to the living organisms is poorly recognised and largely disregarded: molybdenum. In this communication, we will present an overview on molybdenum-dependent enzymes (molybdoenzymes), their constitution, reactions catalysed and mechanistic (chemical) strategy followed. The biological roles of this metal will be highlighted, from the biogeocycles performed by prokaryotes to its involvement in higher organisms. Some key examples of the molybdenum relevance to human health and environmental issues related to food and energy will be also discussed. Because in prokaryotes some of the molybdenum biological roles are played by tungsten, the tungstoenzymes will be here also included.
\end{abstract}

$\mathrm{O}$

ano de 2019 foi declarado pela UNESCO como o "Ano Internacional da Tabela Periódica dos Elementos Químicos" para celebrar os 150 anos da sua criação pelo cientista russo Dmitry Mendeleev. Quisemos aproveitar esta comemoração para dar o merecido destaque ao molibdénio, um elemento químico cuja importância para os organismos vivos é pouco conhecida. Neste artigo, é apresentada uma visão geral sobre as enzimas dependentes de molibdénio (molibdoenzimas), a sua constituição, reações que catalisam e a estratégia mecanística (química) que seguem. É dado destaque aos vários papéis biológicos desempenhados por este metal, desde os ciclos biogeoquímicos envolvendo procariontes, até ao seu envolvimento em organismos superiores. São ainda discutidos alguns exemplos da relevância do molibdénio para a saúde humana e para problemas ambientais relacionados com alimentação e energia. Uma vez que, em procariontes, algumas das funções biológicas do molibdénio são desempenhadas pelo tungsténio, as tungstoenzimas são também incluídas nesta revisão.

\section{Abreviaturas}

AO, aldeído oxidase; AOR, aldeído oxidorredutase; Asp, resíduo de aspartato; Cys, resíduo de cisteína; DMS, sulfureto de dimetilo; DMSO, sulfóxido de dimetilo; DMSOR, sulfóxido de dimetilo redutase; eucar., eucariota; FDH, formato desidrogenase; mARC, denominação internacional da enzima mitocondrial responsável pela redução da amidoxima (do inglês "mitochondrial amidoxime reducing component"); procar., procariota; NaR, nitrato redutase; NO; radical óxido nítrico ('NO); SeCys, resíduo de selenocisteína; Ser, resíduo de serina; SO, sulfito oxidase; ROS, espécies reativas de oxigénio; $\mathrm{XO}$, xantina oxidase.

\section{Introdução}

\subsection{Do século XVIII ao XXI, da Mineralogia à Sociedade e à} Bioquímica

Ao contrário de outros metais, como o ferro, cobre, prata, ouro, mercúrio ou o chumbo, que já eram conhecidos desde a antiguidade, o molibdénio e o tungsténio só foram descobertos muito recentemente, no último quartel do século XVIII [1]. Embora o mineral de molibdénio molibdenite $\left(\mathrm{MoS}_{2}\right.$ (Figura 1)) já fosse conhecido anteriormente, este era confundido com a grafite e a galena (minerais de carbono e chumbo $\left(\mathrm{PbS}_{2}\right)$, respetivamente), um facto refletido no seu nome, que vem da palavra grega "Mo $\lambda \cup \beta \delta o \varsigma^{\prime \prime}$ (Molybdos), que significa chumbo. Curiosamente, o molibdénio já era usado no fabrico de espadas dos guerreiros japoneses do século XIV, embora a sua identidade no Oriente fosse igualmente desconhecida. Só em 1778 Carl Wilhelm Scheele (Figura 1) pôs fim à confusão entre os três mine-

(a) Este artigo foi escrito de acordo com as regras editoriais do QUíMICA, embora a autora LBM use a palavra enzima no masculino. rais, quando oxidou a molibdenite (com ácido nítrico) e produziu um pó branco que ele denominou de ácido molíbdico $\left(\mathrm{MoO}_{3} \cdot \mathrm{H}_{2} \mathrm{O} / \mathrm{H}_{2} \mathrm{MoO}_{4}\right)$. Scheele e Torbern Bergman (o seu amigo de toda a vida) tiveram a intuição que se tratava de um óxido de um novo elemento metálico, mas não o conseguiram isolar. Scheele pediu, então, ajuda a um outro amigo, Peter Jacob Hjelm, em Uppsala (Suécia), o qual, no outono de 1781, conseguiu reduzir o ácido molíbdico e convertê-lo num pó metálico cinzento escuro, o qual ficou conhecido como molibdénio.

A história da descoberta do tungsténio é paralela e contemporânea à do molibdénio. No século XVIII, um mineral branco pesado, existente na Suécia, já era conhecido como "tungsténio", uma alusão à expressão sueca "tung sten", que significa "pedra pesada", mas a sua natureza não era conhecida. Este mineral, $\mathrm{CaWO}_{4}$, é hoje denominado de scheelite, em homenagem a Scheele (Figura 1). Alguns dos primeiros mineralogistas pensavam que se tratava de um mineral de ferro, enquanto que outros sugeriam que continha estanho. Nesta cronologia, é de salientar que, já um século antes (XVII), os chineses usavam um pigmento de 
"tungsténio" (desconhecido no Ocidente) para incorporar uma cor única de pêssego nas suas peças de porcelana, embora também desconhecessem a sua natureza. Só em 1779 Peter Woulfe examinou o mineral e sugeriu que continha um novo metal e, dois anos mais tarde (1781), Scheele isolou um óxido branco que denominou de ácido túngstico. Tal como no caso do molibdénio, Scheele e Bergman tiveram a intuição que se tratava do óxido de um novo metal, mas não o isolaram. Dois anos mais tarde (1783), em Vergara (Espanha), os irmãos espanhóis Juan e Fausto Elhujar, colaboraram no estudo do "tungsténio" e volframite (um mineral castanho escuro; (Fe,Mn)WO (Figura 1)) e, após produzirem o mesmo óxido que Scheele descrevera, conseguiram reduzi-lo e convertê-lo finalmente em tungsténio metálico.

O uso generalizado destes dois metais, porém, só começaria no século XX, quando as suas propriedades começaram a ser melhor entendidas e exploradas: ambos possuem ponto de fusão elevado (o tungsténio tem o mais elevado e o molibdénio o sexto maior de todos os metais conhecidos (Figura 4, secção 3)) e formam ligas estáveis e de elevada dureza com o carbono [2,3]. São por isso usados na fabricação de ligas metálicas resistentes e de superligas ("aços especiais"; ca. 80\% da produção mundial de molibdénio), utilizadas em ferramentas de corte e perfuração, na indústria mineira e petrolífera, em pontes e edifícios e até em dispositivos médicos. O tungsténio, em particular, foi muito usado na indústria bélica nas duas Grandes Guerras Mundiais (altura em que se atingiu o auge da sua exploração nas minas da Panasqueira, em Portugal). Estes metais são também usados em várias aplicações onde são necessárias temperaturas e pressões elevadas (ca. 14\% da produção mundial de molibdénio), como por exemplo nos fornos industriais, lubrificantes sólidos, catalisadores, elétrodos, pigmentos. Certamente que as lâmpadas incandescentes com filamento de tungsténio (agora eliminadas dos nossos edifícios por não serem energeticamente eficientes) são o exemplo mais popular da utilização do tungsténio. Quanto ao molibdénio, um dos exemplos mais elegantes da sua utilização está na estrutura metálica da famosa Pirâmide na entrada do Museu do Louvre, em Paris.

O reconhecimento da presença e essencialidade do molibdénio para os organismos vivos ocorreu ainda mais recentemente. Foi apenas nas décadas de 1950 e 1960, que Bray, Beinert, Lowe, Massey, Palmer, Ehrenberg, Pettersson, Vänngård, Hanson e outros, numa série de estudos inovadores de espetroscopia de ressonância paramagnética eletrónica, demonstraram que as enzimas xantina oxidase (XO) de bovino e sulfito oxidase (SO) de galinha (Figura 2; eq. 2 e 8, respetivamente, no Quadro 1) continham $\mathrm{Mo}^{5+}$ (catião com um eletrão desemparelhado num orbital $d$ (secção 3), logo paramagnético), o qual era essencial à atividade enzimática e podia ser reduzido a $\mathrm{Mo}^{4+}$ ou oxidado a $\mathrm{Mo}^{6+}$, por ação de substratos daquelas enzimas [5-7].

Teriam de passar mais de duas décadas até que o tungsténio fosse incontestavelmente adicionado à lista dos metais essenciais aos organismos vivos (antes, o tungsténio era visto apenas como antagonista e inibidor das molibdoenzimas dos organismos superiores). Embora se soubesse desde a década de 1970 que o tungsténio estimulava o
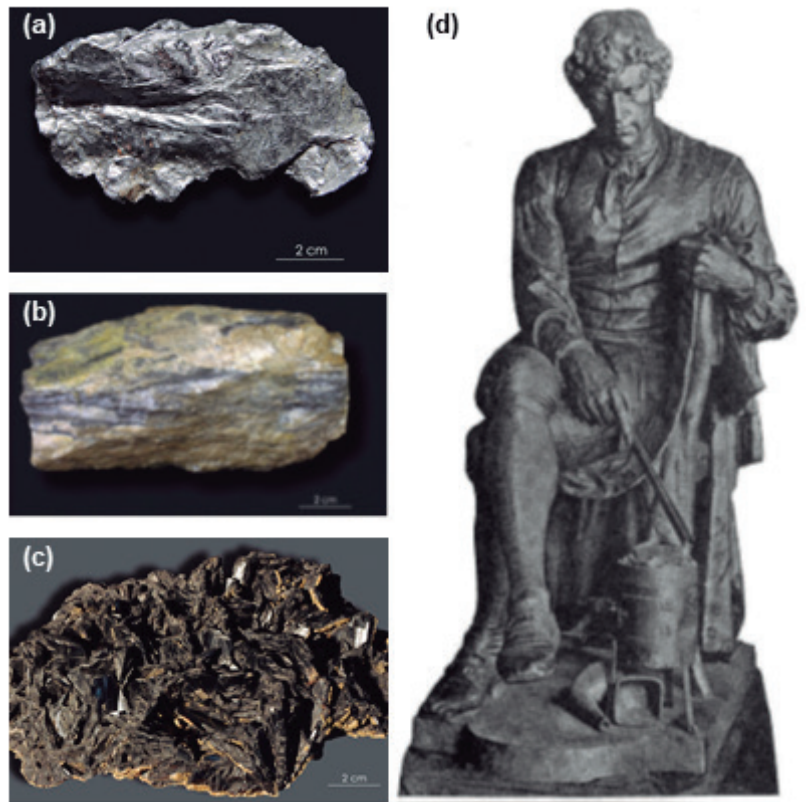

Figura 1 - Minerais de molibdénio e tungsténio e estátua de Carl Wilhelm Scheele, envolvido na sua descoberta. (a) Molibdenite $\left(\mathrm{MoS}_{2}\right)$ - Este mineral de molibdénio encontra-se geralmente em filões hidrotermais de alta temperatura e em granitos e pegmatitos; também pode ser encontrado em depósitos de metamorfismo de contacto. A génese desta amostra está diretamente relacionada com as intrusões graníticas do Maciço de Vila Real em metassedimentos [4]. (b) Scheelite $\left(\mathrm{CaWO}_{4}\right)$ - Este mineral de tungsténio pode encontrar-se em rochas pegmatíticas, filões metalíferos hidrotermais e em depósitos de metamorfismo de contacto. A génese desta amostra está diretamente relacionada com as intrusões graníticas dos Maciços da região do Porto (Mina da Tapada, Gondomar) e a formação de filões hidrotermais em rochas metassedimentares [4]. (c) Volframite $\left((\mathrm{Fe}, \mathrm{Mn}) \mathrm{WO}_{4}\right)$ - Este mineral de tungsténio encontra-se geralmente nos pegmatitos e nos veios de quartzo de alta temperatura associados a granitos; também pode ser encontrada nos veios de sulfuretos e em depósitos aluviais. A génese desta amostra está diretamente relacionada com os processos de formação dos jazigos minerais da Zona Centro-Ibérica e foi recolhida na Mina da Panasqueira, Castelo Branco [4]. As fotografias dos minerais foram gentilmente cedidas pela Doutora Patrícia Marta [4]. (d) Estátua de Carl Wilhelm Scheele da autoria de Börjenson (imagem reproduzida com permissão de [1]).

crescimento de alguns organismos acetógenos e metanógenos, só nos anos 1980 se purificou a primeira enzima contendo tungsténio, uma formato desidrogenase (FDH; Figura 2; eq. 20 no Quadro 1) [8], e se confirmou que a respetiva atividade enzimática dependia deste metal [9]. Porém, o interesse decisivo da comunidade "bio" por este elemento "pesado" só começaria em 1995, quando foi determinada a primeira estrutura cristalina tridimensional de uma tungstoenzima, a aldeído:ferredoxina oxidorredutase de Pyrococcus furiosus (Figura 2; eq. 19 no Quadro 1) [10].

A determinação, quase simultânea, da primeira estrutura cristalina de uma molibdoenzima, a aldeído oxidorredutase (AOR) de Desulfovibrio gigas [11] (Figura 2; eq. 4 no Quadro 1), seguida, em 1996, da estrutura da molibdoenzima sulfóxido de dimetilo redutase (DMSOR) de Rhodobacter sphaeroides [12] (Figura 2; eq. 13 no Quadro 1), permitiu a comparação direta entre molibdo- e tungstoenzimas e mostrou como estas enzimas, aparentemente díspares, estão surpreendentemente relacionadas. Estavam dados os passos determinantes que permitiriam iniciar o século XXI com mais dois metais - molibdénio e tungsténio - na disciplina da "Química da Vida"! 


\subsection{As enzimas}

As molibdo- e tungstoenzimas são enzimas que possuem um ião de molibdénio ou de tungsténio, respetivamente, no seu centro ativo, o qual é essencial à atividade de cada enzima. Além do centro ativo, estas enzimas possuem, na maioria dos casos, outros centros redox adicionais, como centros de ferro/enxofre, hemos ou flavinas (Figura 2), os quais estão envolvidos na transferência eletrónica intra- e intermolecular e/ou na reação com os cossubstratos de cada enzima.

Presentemente, conhecem-se quase uma centena de molibdo- e tungstoenzimas, muitas das quais já caracterizadas bioquímica e estruturalmente, e os estudos genómicos deverão permitir identificar novas enzimas num futuro próximo $[13,14]$. Um exemplo notável dos progressos feitos nos últimos anos é dado pela enzima mitocondrial responsável pela redução da amidoxima (denominada internacionalmente pela sigla mARC; eq. 12 no Quadro 1). Quando se pensava que o "molibdoma" dos humanos estava definido, em 2005 foi identificada mais esta molibdoenzima [15].

A grande maioria das enzimas conhecidas são molibdoenzimas. Estas estão presentes em todas as formas de vida, mas a sua maioria é de origem procariota [13,14]. Os eucariontes possuem um número limitado de molibdoenzimas; os humanos, por exemplo, possuem apenas quatro $X O$, SO, mARC e aldeído oxidase (AO) - e as plantas cinco -as quatro anteriores mais a nitrato redutase (NaR) (eq. 2, 8, 9, 12 e 11, respetivamente, no Quadro 1). Curiosamente, embora todos os organismos superiores usem molibdénio, alguns eucariontes unicelulares perderam a capacidade de usar este elemento (secção 5).

O número de tungstoenzimas conhecidas, todas de origem procariota, é menor do que o de molibdoenzimas (as possíveis razões para esta diferença são discutidas na secção 2) $[16,17]$. As tungstoenzimas encontram-se predominantemente em organismos anaeróbios termófilos, os quais sobrevivem em habitats onde a biodisponibilidade do tungsténio é mais elevada, como em fontes hidrotermais marinhas, mas encontram-se também em bactérias aeróbias e mesófilas.

Ambas as enzimas catalisam reações de oxidaçãoredução, no seu centro ativo de molibdénio/tungsténio, que envolvem a transferência de um átomo de oxigénio, hidrogénio ou enxofre, de e para metabolitos chave $[13,14,16,17]$, como exemplificado pelas enzimas cujas reações estão representadas nas equações do Quadro 1. Várias destas reações constituem passos chave dos ciclos biogeoquímicos do carbono, enxofre e nitrogénio (secção 4), onde se destaca a fixação do nitrogénio atmosférico (redução do $\mathrm{N}_{2}$ a $\mathrm{NH}_{4}^{+}$pela nitrogenase; eq. 1 no Quadro 1), dependente de molibdénio, devido à sua importância para a vida na Terra. O impacto no metabolismo humano é igualmente extraordinário, estando as molibdoenzimas envolvidas em várias condições patológicas, a maioria das quais relacionadas com doenças cardiovasculares e síndromes metabólicos (secção 4).

Nas molibdoenzimas, o ião molibdénio encontra-se coordenado por um de dois tipos de cofatores únicos (Figura 3): o centro heteronuclear de molibdénio e ferro, presente apenas na nitrogenase dependente de molibdénio [18-20], ou o cofator de piranopterina ${ }^{1}$ (uma piranopterina modificada com um grupo cis-ditioleno ( $-\mathrm{S}-\mathrm{CR}=\mathrm{CR}-\mathrm{S}-$ )), presente em todas as outras molibdoenzimas [13,14]. As enzimas com o cofator de piranopterina apresentam ainda um nível adicional de diferenciação, introduzido pela restante esfera de coordenação do molibdénio, a qual pode ser completada por uma segunda molécula de piranopterina e por átomos de oxigénio e/ou enxofre e/ou selénio (Figura 3). As diferentes combinações destes elementos servem de base á classificação das molibdoenzimas em diferentes famílias, denominadas a partir de uma enzima protótipo, XO, SO e DMSOR, como esquematizado na Figura 3 [21].

As tungstoenzimas apresentam uma menor variabilidade $[16,17]$. Nestas, o ião de tungsténio encontra-se coordenado por duas moléculas do cofator de piranopterina e por átomos de oxigénio e/ou enxofre e/ou selénio, formando apenas uma família, a qual partilha os denominadores estruturais da família da DMSOR das molibdoenzimas (Figura 3).

É esta diversidade de arquiteturas do centro metálico que, juntamente com a diversidade do restante centro ativo da enzima (parte proteica), permite que estes dois metais catalisem a diversidade de reações exemplificada no Quadro $1 .^{2}$ Os organismos vivos aprenderam a explorar a Química destes metais (secção 3) e evoluíram para os usar na diversidade de processos metabólicos que é discutida na secção 4. Na secção 2, é apresentada uma perspetiva geral sobre a evolução e disseminação destas enzimas.

\section{Evolução e disseminação das enzimas e a biodis- ponibilidade dos metais}

O molibdénio e o tungsténio estão presentes na Terra em quantidades muito pequenas (Tabela 1). Contudo, a elevada solubilidade do ião molibdato $\left(\mathrm{MoO}_{4}^{2-}\right)$, formado quando os minerais de molibdénio entram em contacto com o dioxigénio e água, aumenta consideravelmente a sua biodisponibilidade e, presentemente, o molibdénio é o metal de transição mais abundante nos oceanos (presente numa concentração de $c a$. $110 \mathrm{nM}$ ). A biodisponibilidade de tungsténio, pelo contrário, é limitada. Este metal encontra-se, por exemplo, em fontes hidrotermais marinhas, onde as condições euxínicas (anóxicas e sulfídicas) favorecem a solubilização de sulfuretos de tungsténio $\left(\mathrm{WS}_{4}{ }^{2-}\right.$ ) [22,23]. Esta diferente solubilidade dos sais de molibdénio e de tungsténio está provavelmente na base da atual distribuição desigual de molibdo- e tungstoenzimas pelas diferentes formas de vida e habitats (secção 1.2) e poderá ter sido a responsável pela evolução díspar destas enzimas.

Muito simplificadamente [14], nas condições euxínicas da Terra primitiva, o tungsténio deverá ter existido na

\footnotetext{
Este cofator é, por vezes, denominado de "molibdopterina", pois foi primeiro identificado nas molibdoenzimas. No entanto, esta denominação antiga é enganadora, uma vez que o mesmo cofator está presente nas tungstoenzimas, como descrito abaixo. Neste artigo, este cofator é denominado simplesmente por "piranopterina".

2 Notar que são conhecidas outras proteínas contendo molibdénio e tungsténio, em particular todas as envolvidas na síntese destas enzimas e no transporte e homeostase dos metais, mas estas não são classificadas como molibdo- e tungstoenzimas e não serão por isso mencionadas nesta revisão.
} 

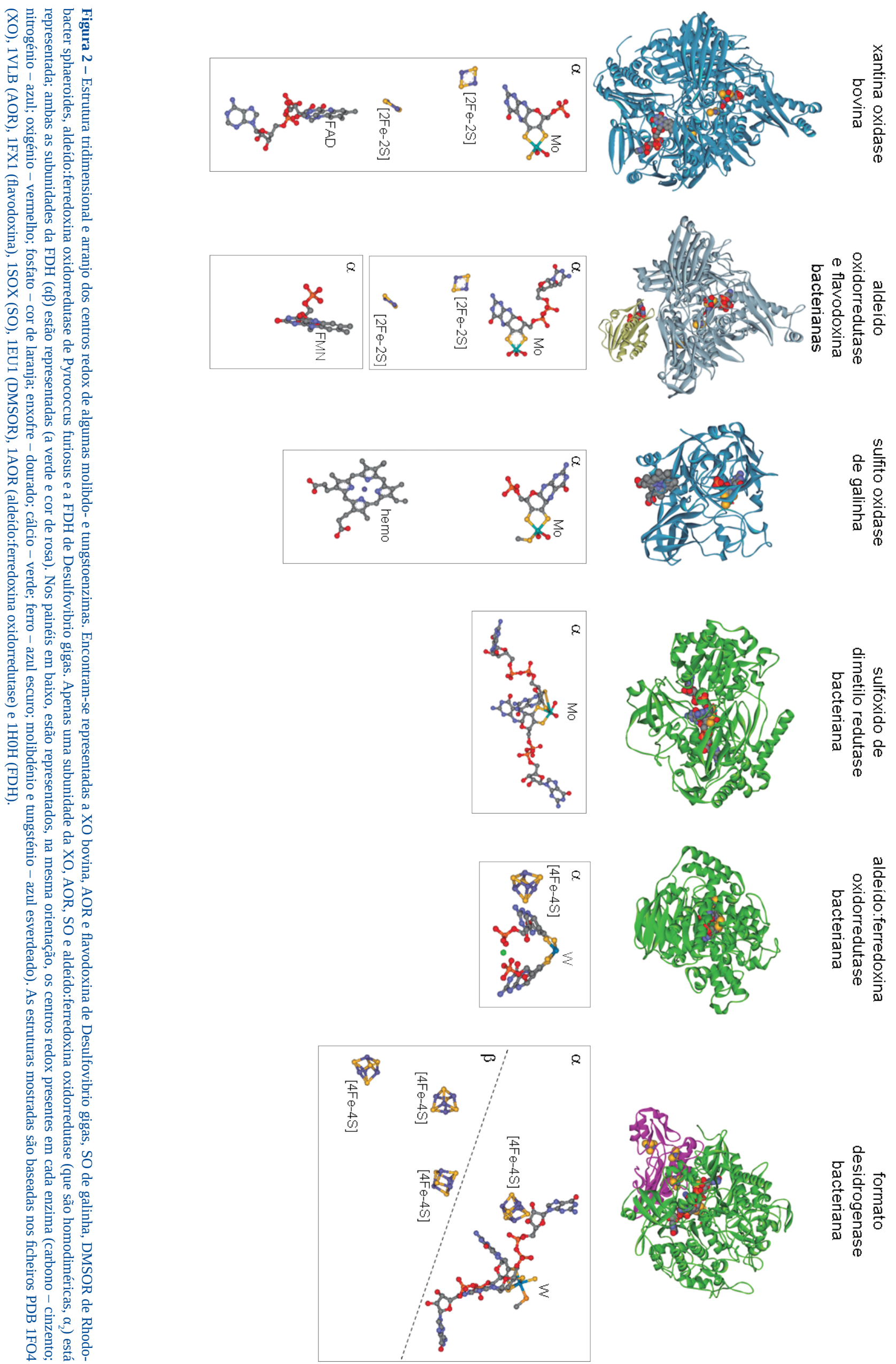
Quadro 1 - Alguns exemplos de molibdo- e tungstoenzimas e respetivas reações.

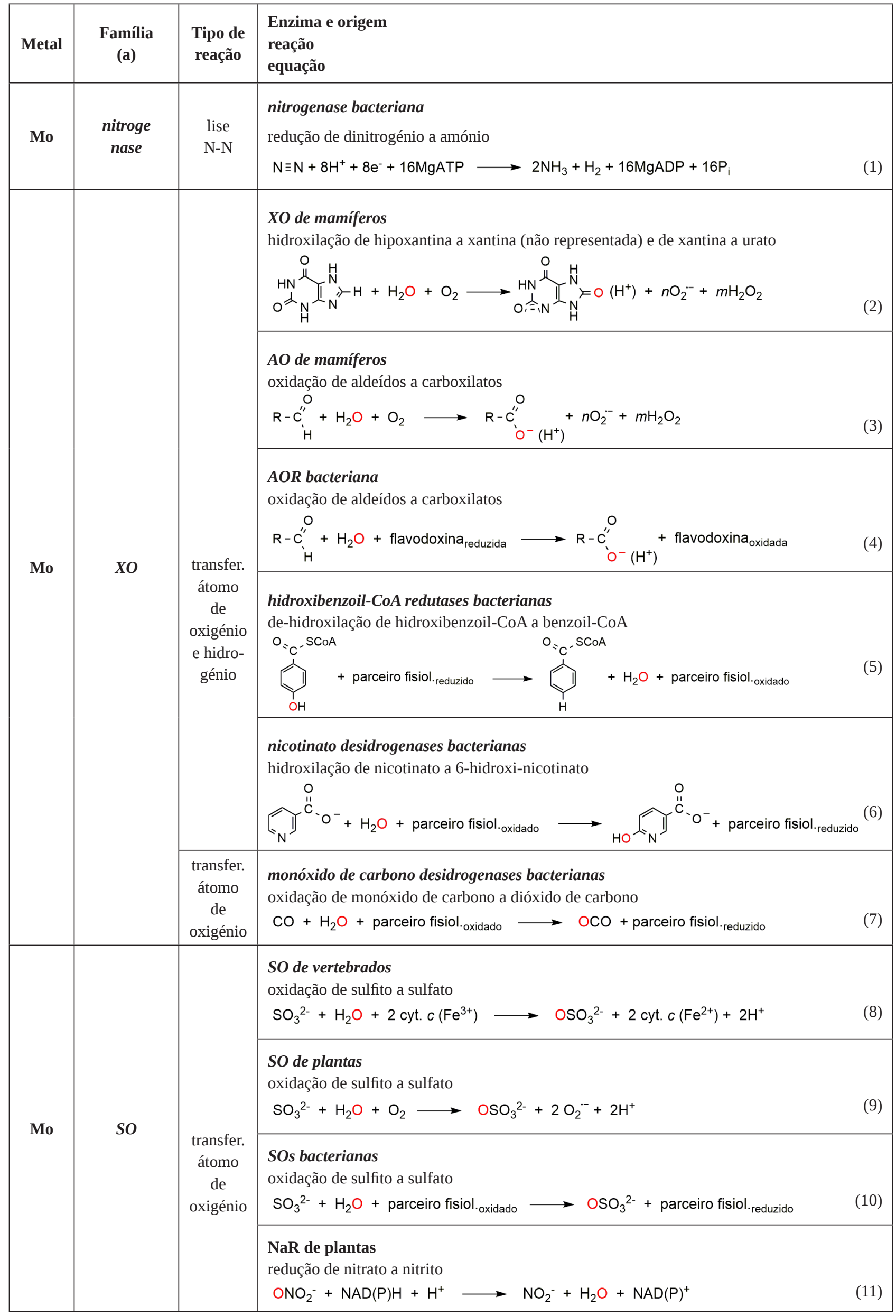




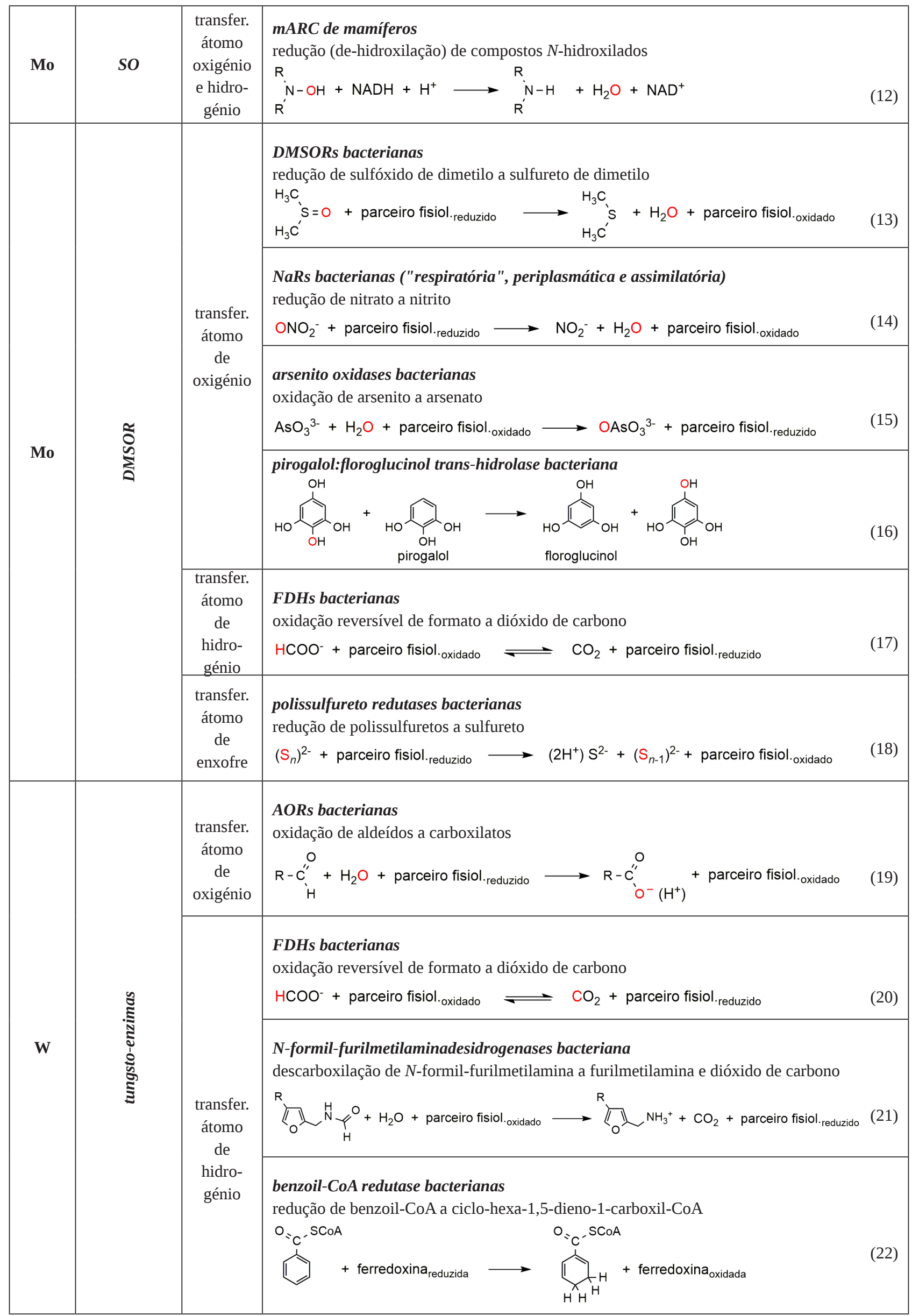

(a) Os centros ativos de cada família de enzimas estão indicados na Figura 3. 


\section{centro metálico}

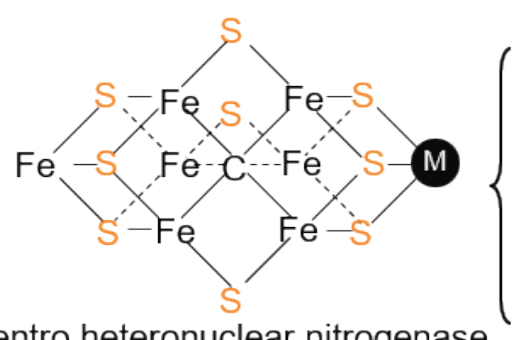

metal

centro ativo

Mo

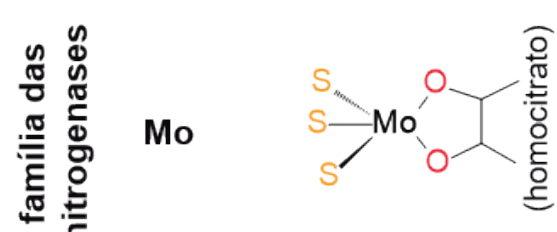

Mo

Mo

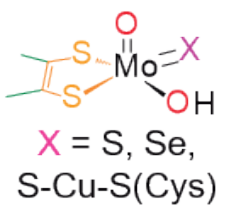

exemplos

nitrogenases

dependentes de Mo

centro heteronuclear nitrogenase

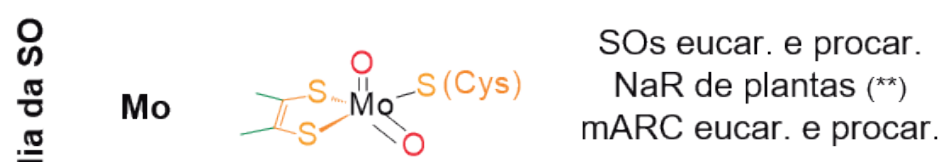

$\mathrm{XO}, \mathrm{AO}, \mathrm{AOR}$

eucar. e procar.

$(X=S)$

nicotinato desidrog.

procar.

$(\mathrm{X}=\mathrm{Se})$

CO desidrogenase

procar.

$(\mathrm{X}=\mathrm{S}-\mathrm{Cu}-\mathrm{S}(\mathrm{Cys}))\left({ }^{\star}\right)$

todos procar.

DMSOR

( $\mathrm{X}, \mathrm{Z}=\mathrm{O}$, Ser)

$\mathrm{NaR}$ "respiratória"

$\left(\mathrm{X}, \mathrm{Z}=\mathrm{O}\right.$, Asp) $\left.{ }^{(\star \star}\right)$

$\mathrm{NaR}$ periplasmática

Mo

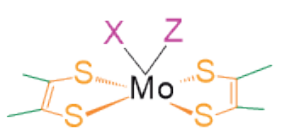

$\mathrm{X}, \mathrm{Z}=\mathrm{S}, \mathrm{Se}, \mathrm{O}, \mathrm{Asp}$, Ser, Cys, SeCys em coord. variável

$(\mathrm{X}, \mathrm{Z}=\mathrm{S}, \mathrm{Cys})\left(^{(\star}\right)$

$\mathrm{NaR}$ assimilatória

$(\mathrm{X}, \mathrm{Z}=\mathrm{S}, \mathrm{Cys})\left({ }^{\star \star}\right)$

$\mathrm{FDH}$

(X, Z = S, Cys e S, SeCys)

arsenito oxidase

$(\mathrm{X}, \mathrm{Z}=\mathrm{O}, \mathrm{OH})$

polissulfureto redutase

(X, Z = O, Cys)

todos procar.

AOR

$(\mathrm{X}, \mathrm{Z}=\mathrm{O}, \mathrm{OH})$

$\mathrm{FDH}$

w

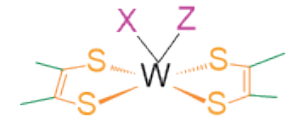

$\mathrm{X}, \mathrm{Z}=\mathrm{S}, \mathrm{Se}, \mathrm{O}$, Asp,

Ser, Cys, SeCys

em coord. variável
(X, Z = S, Cys ou S, SeCys)

$\mathrm{N}$-formilfurilmetilamina desidrog.

(X, Z = S, Cys)

Figura 3 - Famílias de molibdo- e tungstoenzimas. À esquerda, estão representados os dois tipos de cofatores que coordenam o molibdénio e o tungsténio; M representa metal (molibdénio ou tungsténio). O cofator de piranopterina (pirano (verde), pterina (azul), ditioleno (cor de laranja), metilfosfato (preto)) coordena o metal através do grupo ditioleno e, nas estruturas à direita, para simplificar, apenas esta parte do cofator está representada; ao contrário dos eucariontes (onde R representa um átomo de hidrogénio), nos procariontes, a piranopterina encontra-se muitas vezes esterificada com diferentes nucleótidos (R pode ser monofosfato de citidina, de guanosina ou de adenosina). À direita, estão representadas as estruturas dos centros ativos das várias famílias de molibdo- e tungstoenzimas, na forma oxidada, e são indicados alguns membros de cada família; Asp, Ser, Cys, SeCys representam resíduos de aspartato, serina, cisteína e de selenocisteína.

$\left(^{*}\right)$ Na monóxido de carbono desidrogenase, o grupo Mo-OH é substituído por Mo=O.

(**) Notar que os diferentes tipos de NaRs, apesar de catalisarem a mesma reação de redução de nitrato a nitrito, possuem centros ativos diferentes. 
forma de sais de sulfureto relativamente solúveis e, por isso, deverá ter sido mais biodisponível no oceano primitivo do que o molibdénio (que estaria na forma de $\mathrm{MoS}_{2}$ insolúvel). Assim, é provável que o tungsténio tenha sido um elemento essencial para as formas de vida primitivas, tal como hoje o é para os organismos que habitam fontes hidrotermais marinhas, onde a sua biodisponível é elevada [22,23]. Esta provável essencialidade do tungsténio está também alinhada com as propriedades químicas que diferenciam este metal do molibdénio: os compostos de tungsténio apresentam potenciais de redução mais baixos, ligações mais fortes, uma maior estabilidade térmica e uma maior sensibilidade ao dioxigénio, comparativamente a compostos de molibdénio equivalentes. Estas diferenças suportam a hipótese de que o tungsténio terá sido uma melhor escolha para levar a cabo as reações anaeróbias de baixo potencial de redução que terão ocorrido nas condições da Terra primitiva [16,17,22-25]. Posteriormente, o progressivo aumento do dioxigénio (resultado da evolução dos organismos fotossintéticos) deverá ter promovido a "libertação" do molibdénio dos minerais da crosta (solubilização na forma de molibdato) e, simultaneamente, a "remoção" (precipitação) do tungsténio do oceano. Esta transformação ambiental (oxigenação e alterações geoquímicas consequentes) terá, provavelmente, pressionado os organismos a "trocarem" o tungsténio pelo molibdénio. Os organismos terão aprendido a explorar as semelhanças químicas entre os dois metais para desenvolverem novas enzimas que lhes permitissem continuar a catalisar as reações "antigas" e as reações "novas" ditadas pelas necessidades impostas pelo novo ambiente. Esta hipótese é suportada pelo facto de se conhecerem molibdoenzimas homólogas a várias tungstoenzimas, quer em organismos diferentes, quer no mesmo organismo, como é o caso, por exemplo, das AOR e FDH (eq. 4 e 19 (AOR) e 17 e 20 (FDH) no Quadro 1). Este processo poderá, deste modo, ter conduzido à evolução das várias molibdoenzimas que hoje conhecemos, ao mesmo tempo que terá condicionado fortemente o uso generalizado de tungsténio; no limite, este processo terá sido o responsável pelo tungsténio não ser usado por eucariontes, enquanto que o molibdénio é essencial para todas as formas de vida, incluindo os organismos superiores como os humanos. Assim, é provável que ambas as molibdo- e as tungstoenzimas tenham existido no último ancestral comum universal (LUCA). A vida e o planeta Terra certamente evoluíram juntas, num processo complexo onde a geosfera, hidrosfera, atmosfera e biosfera estão intimamente interrelacionadas.

Nos dias de hoje, o número de espécies que usa molibdénio é muito superior ao dos utilizadores de tungsténio. E, embora esta diferente escala de utilização possa ser adequadamente interpretada como sendo resultado da biodisponibilidade dos metais e da evolução da vida, subsistem ainda aspetos intrigantes. Um aspeto obscuro diz respeito à inibição das molibdoenzimas pelo tungsténio e das tungstoenzimas pelo molibdénio: apesar das semelhanças entre as propriedades químicas dos dois metais e do facto de serem coordenados pelo mesmo cofator, as diferenças químicas entre molibdénio e tungsténio são suficientes para interferirem nas propriedades catalíticas das enzimas. Por exemplo, quando ratos [26] e plantas [27] são expostos a tungsténio, estes produzem moléculas de molibdoenzimas (XO, AO, SO e NaR) com tungsténio, as quais não têm atividade enzimática. A substituição por molibdénio da AOR dependente de tungsténio bacteriana conduz igualmente a uma enzima sem atividade [28]. ${ }^{3}$ A situação torna-se verdadeiramente confusa quando olhamos para organismos que contêm simultaneamente molibdo- e tungstoenzimas homólogas e heterólogas. É o caso, por exemplo, de várias bactérias redutoras de sulfato que expressam simultaneamente AORs dependentes de molibdénio e FDHs dependentes quer de molibdénio quer de tungsténio. Claramente, muito ainda há a aprender sobre as escolhas de metais que os organismos fazem para as suas enzimas!

\footnotetext{
Esta inibição é ainda mais enigmática uma vez que se conhecem várias AOR, também bacterianas, dependentes de molibdénio.
}

Tabela 1 - Abundância do molibdénio, tungsténio e outros elementos com relevância biológica em diferentes localizações [2]. Os valores de abundância dizem respeito ao número de átomos por $10^{9}$ átomos. A cor reflete a gama de valores: vermelho, valores inferiores a 1 por cada $10^{9}$ átomos; laranja, valores entre 1 e $10^{3}$ por cada $10^{9}$ átomos; verde-azulado, valores entre $10^{3}$ e $10^{6}$ por cada $10^{9}$ átomos; azul, valores superiores a $10^{6}$ por cada $10^{9}$ átomos.

\begin{tabular}{|c|c|c|c|c|c|}
\hline \multirow{12}{*}{ 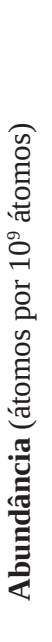 } & Elemento & Universo & Terra - rochas & Terra - oceanos & Corpo humano \\
\hline & Mo & $100 \times 10^{-3}$ & 230 & $640 \times 10^{-3}$ & 7 \\
\hline & W & $3 \times 10^{-3}$ & 120 & $4 \times \mathbf{1 0}^{-3}$ & --- \\
\hline & Mn & 200 & $420 \times 10^{3}$ & $230 \times 10^{-3}$ & 23 \\
\hline & Fe & $20 \times 10^{3}$ & $23 \times 10^{6}$ & $330 \times 10^{-3}$ & $6,7 \times 10^{3}$ \\
\hline & Co & 60 & $10 \times 10^{3}$ & $8 \times 10^{-3}$ & 2 \\
\hline & $\mathrm{Cu}$ & 1 & $22 \times \mathbf{1 0}^{3}$ & $290 \times 10^{-3}$ & 99 \\
\hline & Zn & 6 & $25 \times 10^{3}$ & $470 \times 10^{-3}$ & $3,2 \times \mathbf{1 0}^{3}$ \\
\hline & $\mathbf{H}$ & $930 \times 10^{6}$ & $31 \times \mathbf{1 0}^{\mathbf{6}}$ & $662 \times \mathbf{1 0}^{\mathbf{6}}$ & $620 \times 10^{6}$ \\
\hline & C & $500 \times 10^{3}$ & $3,1 \times 10^{3}$ & $14,4 \times \mathbf{1 0}^{3}$ & $120 \times \mathbf{1 0}^{6}$ \\
\hline & $\mathbf{N}$ & $90 \times 10^{3}$ & $29 \times 10^{3}$ & 220 & $12 \times \mathbf{1 0}^{6}$ \\
\hline & $\mathbf{O}$ & $800 \times 10^{3}$ & $600 \times 10^{6}$ & $331 \times 10^{\mathbf{6}}$ & $240 \times 10^{6}$ \\
\hline
\end{tabular}




\section{A Química relevante para a Bioquímica ${ }^{4}$}

O molibdénio e o tungsténio são metais de transição, pertencentes ao "bloco $d$ " da Tabela Periódica, e têm configuração eletrónica [Kr] $4 d^{5} 5 s^{1}$ e [Xe] $4 f^{14} 5 d^{4} 6 s^{2}$, respetivamente (Figura 4). São metais "pesados", pertencentes aos quinto e sexto períodos, com números atómicos 42 e 74, respetivamente, e têm a particularidade de serem os únicos metais de transição destes períodos "elevados" (logo "pesados") com funções fisiológicas conhecidas.

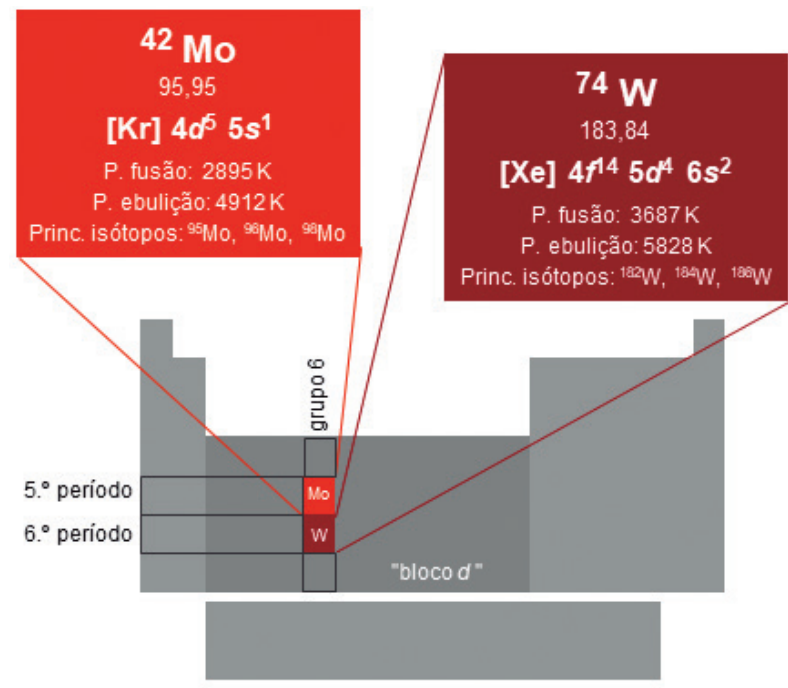

Figura 4 - O molibdénio e o tungsténio na Tabela Periódica dos Elementos Químicos.

A Química (relevante) destes metais é caracterizada por (i) oxidação/redução em condições fisiológicas, entre os estados de oxidação 6+, 5+ e 4+, (ii) formação de óxidos e sulfuretos e (iii) uma grande versatilidade na primeira esfera de coordenação dos seus complexos [23,29-31]. A forte tendência do molibdénio no estado oxidado (6+) para se coordenar a grupos oxo é contrabalançada pela facilidade com que pode perder um átomo de oxigénio no estado reduzido (4+). Esta característica faz com que os complexos de molibdénio sejam excelentes "trocadores de átomos de oxigénio" (eq. 23, onde X representa o metabolito substrato da enzima).

$\mathrm{Mo}^{6+}-\mathrm{O}+\mathrm{X} \rightleftharpoons \mathrm{Mo}^{4+}+\mathrm{X}-\mathrm{O}$

Os organismos vivos aprenderam a explorar esta Química e usam estes metais para catalisar reações de oxidação-redução que envolvem a transferência de um átomo de oxigénio da água para o produto - inserção de um átomo de oxigénio (Figura 5, setas azuis) - ou do substrato para a água - abstração de um átomo de oxigénio (Figura 5, setas verdes) (ver exemplos de reações no Quadro 1). Nestas reações, (i) a molécula de água atua como dador ou aceitador primário do átomo de oxigénio, (ii) o metal é o dador ou aceitador direto do átomo de oxigénio e (iii) o estado de oxidação do metal determina a direção da transferência, i.e., o centro metálico oxidado (6+) doa o átomo de oxigénio e o centro metálico reduzido (4+) aceita o átomo de oxigénio (Figura 5) [13,14]. Esta estratégia química é claramente diferente da usada nas monooxigenases, os

\footnotetext{
4 Nesta secção, não será incluída a nitrogenase pois o mecanismo reacional atualmente aceite para esta enzima envolve apenas os átomos de ferro e enxofre do centro catalítico [18-20].
}

"adicionadores" de átomos de oxigénio mais conhecidos. As monooxigenases (enzimas hémicas) catalisam a hidroxilação do seu substrato usando o dioxigénio como fonte do átomo de oxigénio a inserir (e não a água). Além disso, as monooxigenases consomem equivalentes redutores (cocatalisam a oxidação do seu parceiro fisiológico; NAD(P) $\left.\mathrm{H} \rightarrow \mathrm{NAD}(\mathrm{P})^{+}\right)$, enquanto que nas suas reações de inserção de um átomo de oxigénio, as molibdo- e tungstoenzimas geram equivalentes redutores (quando o $\mathrm{Mo}^{4+} / \mathrm{W}^{4+}$ formado é regenerado ao estado inicial, $\mathrm{Mo}^{6+} / \mathrm{W}^{6+}$; Figura 5).

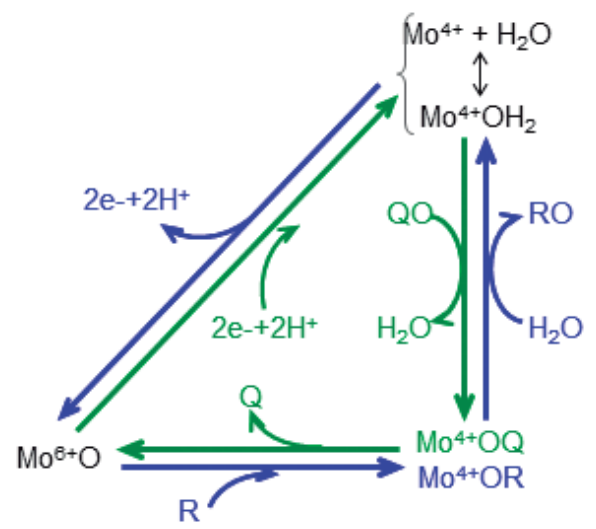

Figura 5 - Mecanismo de transferência de átomo de oxigénio. Inserção de um átomo de oxigénio, setas azuis; abstração de um átomo de oxigénio, setas verdes. A inserção de um átomo de oxigénio pode ser exemplificada pela reação de oxidação do sulfito (R) a sulfato (RO) catalisada pela SO, ou pela hidroxilação da xantina $(\mathrm{R})$ a urato $(\mathrm{RO})$ catalisada pela XO. Nestas enzimas, é o $\mathrm{Mo}^{6+}=\mathrm{O}_{\text {(equatorial) }}$ que atua como dador direto do átomo de oxigénio. A abstração de um átomo de oxigénio pode ser exemplificada pela reação de redução do nitrato $(\mathrm{QO})$ a nitrito $(\mathrm{Q})$ catalisada pela NaR de plantas, ou pela redução de sulfóxido de dimetilo (QO) a sulfureto de dimetilo (Q) catalisada pela DMSOR bacteriana. Nestas enzimas, é o centro reduzido $\mathrm{Mo}^{4+}$, cujo grupo oxo foi eliminado na forma de uma molécula de água, que atua como aceitador direto do átomo de oxigénio; o mesmo mecanismo é seguido pela DMSOR (ver as estruturas dos centros ativos na Figura 3). Em todos os casos, o dador ou aceitador primário do átomo de oxigénio é uma molécula de água; o metal é reoxidado/rerreduzido através da transferência de eletrões para/de o parceiro fisiológico da enzima (isto é, o parceiro fisiológico atua apenas como o substrato oxidante ou redutor).

É devido à catálise de hidroxilação, atualmente bem estabelecida, que as molibdo- e tungstoenzimas são frequentemente chamadas de hidoxilases ou oxo-transferases. Mas esta generalização é incorreta, pois a versatilidade química destas enzimas permite que estas catalisem igualmente a transferência de um átomo de enxofre ou hidrogénio, como é o caso, por exemplo, da polissulfureto redutase (eq. 18 no Quadro 1) e da FDH (eq. 17 e 20 no Quadro 1), respetivamente $[13,14]$.

A catálise da transferência de um átomo de hidrogénio é suportada por uma outra característica destes centros metálicos: o $\mathrm{p} K_{\mathrm{a}}$ dos ligandos do metal é tal que os estados de oxidação mais baixos possuem os ligandos protonados, enquanto que nos estados de oxidação mais elevados os ligandos estão favoravelmente desprotonados. Esta propriedade permite que o ligando terminal de enxofre do centro ativo destas enzimas catalise a transferência de um átomo de hidrogénio do centro metálico reduzido $\left(\mathrm{Mo}^{4+} / \mathrm{W}^{4+}-\mathrm{SH}\right)$ para o substrato - inserção de um átomo de hidrogénio (Figura 6, setas verdes) - ou do substrato para o centro me- 
tálico oxidado $\left(\mathrm{Mo}^{6+} / \mathrm{W}^{6+}=\mathrm{S}\right)$ - abstração de um átomo de hidrogénio (Figura 6, setas azuis) (ver exemplos de reações no Quadro 1) [14,32-35]. Nestas reações, há a transferência concomitante de dois eletrões, pelo que a catálise é, na realidade, de transferência de hidreto. A fonte primária (dador e aceitador) do átomo de hidrogénio é a água e, mais uma vez, o estado de oxidação do metal determina a direção da transferência, i.e., o centro metálico oxidado (6+) aceita o átomo de hidrogénio e o centro metálico reduzido (4+) doa o átomo de hidrogénio (Figura 6).

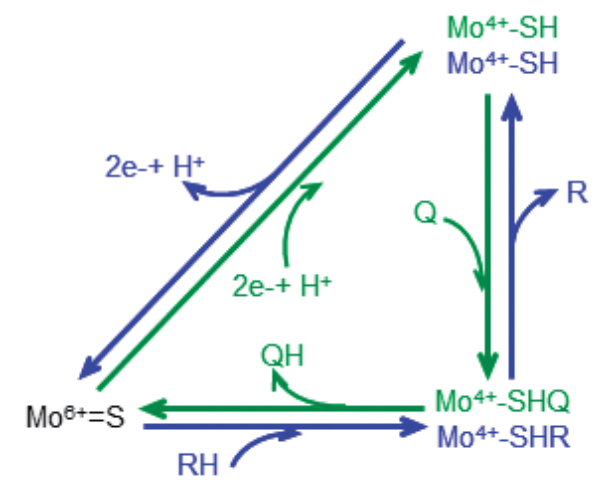

Figura 6 - Mecanismo de transferência de átomo de hidrogénio. Abstração de um átomo de hidrogénio, setas azuis; inserção de um átomo de hidrogénio, setas verdes. A abstração de um átomo de hidrogénio pode ser exemplificada pela reação de oxidação do formato $(\mathrm{RH})$ a dióxido de carbono (R) catalisada pela FDH, ou pela hidroxilação da xantina $(\mathrm{RH})$ a urato (R) catalisada pela XO. Nestas enzimas, é o $\mathrm{Mo}^{6+}=\mathrm{S}$ que atua com aceitador direto do átomo de hidrogénio. A inserção de um átomo de hidrogénio pode ser exemplificada pela reação de redução do dióxido de carbono (Q) a formato $(\mathrm{QH})$ catalisada pela $\mathrm{FDH}$, onde é o $\mathrm{Mo}^{4+}-\mathrm{SH}$ que atua como dador direto do átomo de hidrogénio (ver as estruturas dos centros ativos na Figura 3). Em todos os casos, o dador ou aceitador primário do átomo de hidrogénio é uma molécula de água; o metal é reoxidado/ rerreduzido através da transferência de eletrões para/de o parceiro fisiológico da enzima (isto é, o parceiro fisiológico atua apenas com substrato oxidante ou redutor).

Nesta breve secção, não pode deixar de ser mencionado o papel decisivo que a parte proteica do centro ativo da enzima desempenha na Química destes metais. Além de contribuir para "selecionar" as moléculas que serão transformadas pela enzima, o centro ativo condiciona a geometria (logo a estrutura eletrónica) do centro metálico [13,14]. O centro ativo determina ainda a segunda esfera de coordenação do centro metálico e, em muitos casos, também a primeira esfera de coordenação, como é o caso das enzimas da família da SO, DMSOR e tungstoenzimas (Figura 3). O "desenho" do centro ativo permite, assim, que centros metálicos semelhantes possam ser usados em enzimas com funções díspares, como é o caso, por exemplo, da FDH e da NaR periplasmática.

A estrutura que coordena o metal diretamente - uma ou duas moléculas de piranopterina (Figura 3) - desempenha igualmente um papel importante na catálise, nomeadamente na transferência eletrónica para os outros centros redox da enzima, atuando com um "fio condutor" [36-38] (notar que, salvo poucas exceções, os molibdo- e tungstoenzimas possuem um ou mais centros redox adicionais (Figura 2)). É, no entanto, difícil racionalizar qual a vantagem de um centro ativo possuir duas moléculas de piranopterina, face a ter só uma, uma vez que apenas uma piranopterina está envolvida na transferência de eletrões (a que estiver mais próxima do centro redox com o qual ocorre a transferência eletrónica). Foi recentemente sugerido que a segunda molécula de piranopterina é essencial para modular o potencial de redução do centro metálico e, assim, facilitar a transferência eletrónica no sentido correto para o metabolismo do organismo (redução ou oxidação do substrato) [39]. O centro ativo da enzima desempenha aqui um papel igualmente decisivo ao controlar a conformação (logo a estrutura eletrónica) das moléculas de piranopterina [40]. Esta sugestão, assim como o possível envolvimento da segunda molécula de piranopterina na catálise química, é, contudo, contestada por enzimas como as que catalisam, por exemplo, a redução de nitrato a nitrito, as quais tanto podem ter duas, como apenas uma molécula de piranopterina a coordenar o ião de molibdénio (Figura 3).

Por fim, o papel do próprio metal: qual a vantagem do uso de um metal face ao outro? Uma vez que, comparativamente, os compostos de tungsténio apresentam potenciais de redução mais baixos, ligações mais fortes, uma maior estabilidade térmica e uma maior sensibilidade ao dioxigénio, este metal parece ser adequado à catálise de reações anaeróbias, de baixo potencial de redução (como discutido na secção 2). Várias tungstoenzimas suportam esta ideia, como a benzoil-CoA redutase, AOR, $N$-formil-furilmetilamina desidrogenase ou a FDH (eq. 22, 19, 21, 20, respetivamente, no Quadro 1), que catalisam reações cujo potencial de redução é $-622 \mathrm{mV},-580 \mathrm{mV},-500 \mathrm{mV}$ e $-430 \mathrm{mV}$, respetivamente [13,14]. Também o facto de não se conhecer nenhuma $\mathrm{NaR}(+420 \mathrm{mV})$ dependente de tungsténio está em concordância. Por outro lado, as molibdoenzimas conhecidas mostram que o molibdénio é muito mais versátil do que o tungsténio: é apropriado para catalisar reações tanto de elevado (por exemplo, a $\mathrm{NaR}$ ), como de baixo potencial de redução (AOR e FDH dependentes de molibdénio), quer em condições aeróbias, quer anaeróbias [13,14]. Segundo esta perspetiva, a utilização de molibdénio (em detrimento de tungsténio) seria uma "melhor escolha" para os organismos vivos, pois um só metal permitiria realizar diferentes tipos de catálise. Aparentemente, é apenas em condições de elevada temperatura (em organismos termófilos) que o uso de tungsténio será mais vantajoso do ponto de vista meramente químico. Deve, contudo, ser salientado que "mais vantajoso quimicamente" não quer dizer que seja a única escolha do organismo, pois outros fatores subjacentes à evolução da vida determinam a utilização de metais. E, de facto, tal como discutido na secção 2, conhecem-se vários organismos que expressam simultaneamente molibdo- e tungstoenzimas.

\section{A vida com molibdénio}

Quando pensamos nos elementos químicos que são essenciais à vida na Terra, raramente nos lembramos do molibdénio. Contudo, o nosso planeta seria muito diferente sem molibdénio! Este metal teve e tem um grande impacto em diferentes ciclos biogeoquímicos, em particular no ciclo do nitrogénio (Figura 7). 


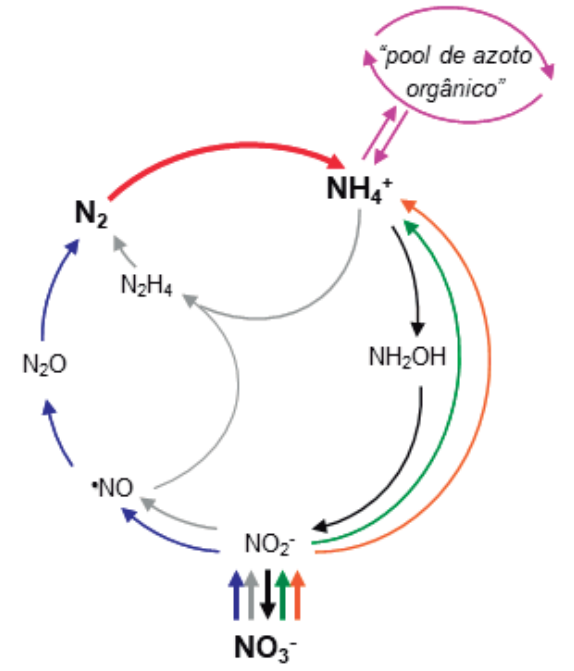

Figura 7 - Ciclo biogeoquímico do nitrogénio. Está representada apenas a parte levada a cabo pelos organismos vivos. Fixação de dinitrogénio (via assimilatória), seta vermelha; amonificação assimilatória (via assimilatória), setas verdes; redução dissimilatória de nitrato a amónio (via "respiratória"), setas cor de laranja; "pool" de nitrogénio orgânico, setas cor de rosa; oxidação anaeróbia do amónio (via "respiratória"), setas cinzentas; nitrificação e oxidação de amónio (ambas via "respiratória"), setas pretas; desnitrificação (via "respiratória"), setas azuis. Os passos dependentes de molibdénio estão representados com linhas mais grossas; as formas de nitrogénio que representam pontos-chave do ciclo, dinitrogénio, nitrato e amónio, estão representadas a negrito. Imagem adaptada com permissão de [41].

O nitrogénio é o quarto elemento mais abundante nos organismos vivos (os três mais usados são o hidrogénio, oxigénio e carbono; os valores nos humanos estão indicados na Tabela 1). Este elemento é usado na biossíntese de aminoácidos, nucleósidos e outros compostos fundamentais à vida. A vida na Terra depende, por isso, de vias metabólicas que convertem o nitrogénio na forma que é usada para fins biossintéticos - o amónio (Figura 7) [41-45]: (i) a via da fixação do dinitrogénio atmosférico $\left(\mathrm{N}_{2}\right.$, a maior fonte de nitrogénio do planeta; 78\% da atmosfera da Terra), (ii) a via da amonificação assimilatória que usa nitrato e ainda (iii) a via da redução dissimilatória do nitrato a amónio (embora esta seja uma via "respiratória", ela também conduz à produção de amónio que pode ser usado para fins biossintéticos). Todas estas vias dependem de molibdénio. Os organismos que fixam o dinitrogénio atmosférico (simbiontes e de "vida livre", como, por exemplo, Rhizobium e Azotobacter, respetivamente) dependem da nitrogenase dependente de molibdénio para catalisar a redução direta de dinitrogénio a amónio (eq. 1 no Quadro 1; Figura 7, seta vermelha) e são responsáveis pela produção de $c a$. $90 \%$ do nitrogénio biodisponível. Os organismos que levam a cabo a amonificação assimilatória (organismos fotossintéticos como cianobactérias e os cloroplastos dos eucariontes fotossintéticos e organismos heterotrofos e fototrofos, como Rhodobacter capsulatus) dependem da NaR assimilatória para catalisar o passo inicial de redução de nitrato a nitrito (eq. 11 e 14 no Quadro 1; Figura 7, setas verdes). Também os organismos que usam o nitrato na "respiração" utilizam uma NaR que é dependente de molibdénio (eq. 14; Figura 7 , setas cor de laranja). Todos os outros organismos, procariontes e eucariontes - a vasta maioria da vida na Terra, nós próprios incluídos - dependem do amónio disponível no ambiente (crosta/solos e oceanos/rios) e/ou de cadeias alimentares. Com este cenário em mente, certamente que o papel biológico do molibdénio assume outra dimensão!

Se o papel atual do molibdénio no ciclo do nitrogénio é impressionante, o efeito deste metal na vida primitiva é ainda mais extraordinário [14,42,46-48]. Como discutido na secção 2, nas condições euxínicas da Terra primitiva, a biodisponibilidade de molibdénio deverá ter sido muito limitada. Esta escassez de molibdénio deverá, provavelmente, ter impedido a evolução mais atempada de uma nitrogenase eficiente e, por isso, pensa-se que terá ter sido a responsável pelo "atraso" de 2000 milhões de anos na evolução e expansão da vida na Terra.

Mas o nitrogénio e o molibdénio não são obrigatórios apenas para fins biossintéticos. Ambos os elementos são também essenciais para as vias dissimilatórias de alguns organismos que usam compostos de nitrogénio em "cadeias respiratórias", ou seja, como fonte de energia [4145]. É o caso das vias de desnitrificação (Figura 7, setas azuis), redução dissimilatória de nitrato a amónio (Figura 7, setas cor de laranja), oxidação anaeróbia do amónio (Figura 7, setas cinzentas) e nitrificação (Figura 7, setas pretas). Todas estas vias dependem da redução do nitrato a nitrito (as primeiras três) e da oxidação do nitrito a nitrato (nitrificação), duas reações que são (tanto quanto se sabe) exclusivamente dependentes de molibdénio (enzimas NaR e nitrito redutase).

A participação do molibdénio no ciclo do nitrogénio, em pontos-chave que controlam a entrada do nitrogénio na biosfera, faz com que este metal desempenhe um papel crítico em vários dos problemas ambientais que a nossa Sociedade enfrenta, como discutido na "Caixa 1 - Ambiente e alimentação".

O binómio molibdénio/nitrogénio está ainda envolvido num outro processo fisiológico não relacionado com o ciclo do nitrogénio, mas que se apresenta como uma "cópia" (herança?) dos primeiros passos da via da desnitrificação (Figura 7, setas azuis): a via de sinalização celular em humanos "nitrato -nitrito - óxido nítrico" (eq. 24) [49-53]. O radical óxido nítrico ( $\mathrm{NO}$, abreviado como NO) é uma molécula sinalizadora envolvida em vários processos fisiológicos, como a vasodilatação, agregação plaquetária, neurotransmissão ou a expressão genética, cuja formação, em condições de normóxia, é catalisada por NO sintases específicas. Porém, em condições de hipóxia (quando a disponibilidade de dioxigénio é limitada e a atividade das NO sintases está comprometida), a formação de NO é catalisada pelas XO e AO (eq. 25 e 26), as quais contribuem assim para a sobrevivência celular em condições de stresse. As mesmas reações (eq. 24 e 26) têm sido sugeridas em vias de sinalização em plantas e bactérias, onde a formação de NO é catalisada pela $\mathrm{NaR}$ de plantas [41,54] e pelas AOR [41,51,52] e NaR [41,55,56] de bactérias.

$$
\begin{aligned}
& \mathrm{NO}_{3}{ }^{-} \longrightarrow \mathrm{NO}_{2}{ }^{-} \longrightarrow{ }^{-} \mathrm{NO} \\
& \mathrm{NO}_{3}{ }^{-}+\text {parceiro fisiol. } \\
& \mathrm{NO}_{2}{ }^{-}+\text {parceirozido fisiol. }
\end{aligned}
$$

O molibdénio está também envolvido no biogeociclo de outro elemento essencial para os organismos vivos: o carbono. Ainda que não seja o único, ou o principal inter- 
veniente, o molibdénio contribui para a fixação do carbono. A FDH (dependente de molibdénio ou de tungsténio; eq. 17 e 20 no Quadro 1) é usada por organismo acetógenos para catalisar a redução do dióxido de carbono atmosférico a formato, em vias metabólicas que produzem acetato, usando muitas vezes di-hidrogénio como o redutor direto ou final (como é o caso de Acetobacterium woodii ou Clostridium carboxidivorans, respetivamente) $[35,57,58]$. As FDHs são igualmente usadas por um vasto número de organismos que levam a cabo a reação reversa (oxidação de formato a dióxido de carbono), em vias onde o formato é empregue como "substrato" (dador de eletrões) de "cadeias de respiratórias" que acoplam a oxidação do formato à redução de diferentes aceitadores terminais de eletrões, tais como nitrato (por exemplo, E. coli e Desulfovibrio desulfuricans), nitrito (Wolinella succinogenes), sulfato (Desulfovibrio species), sulfuretos (Methanococcus maripaludis), arsenato (Desulfitobacterium) ou até ferro férrico (Geobacter e Shewanella). Dada a sua atividade intrínseca de redução do dióxido de carbono, as FDHs são atualmente alvo de um grande interesse biotecnológico para a mitigação de problemas ambientais, como discutido na "Caixa 2 - A pegada de carbono e a reutilização do dióxido de carbono atmosférico". O molibdénio é também essencial para alguns organismos que crescem com monóxido de carbono como fonte de energia e carbono. Estes organismos, como Oligotropha carboxidovorans e Hydrogenophaga pseudoflava, usam uma enzima monóxido de carbono dependente de molibdénio e cobre para catalisar a oxidação do monóxido de carbono a dióxido de carbono (eq. 7 no Quadro 1) [59].

O papel do molibdénio não é, contudo, restrito ao metabolismo em C1 (biossíntese ou energia), nem nos organismos atuais, nem nos organismos primitivos. Na Terra primitiva, o molibdénio e o tungsténio deverão ter sido essenciais para os organismos ancestrais metabolizarem aldeídos e carboxilatos (simples e complexos), usando AORs específicas (eq. 4 e 19 no Quadro 1) [60]. Também a utilização de compostos heterocíclicos (redução e oxidação, hidroxilação e de-hidroxilação, saturação e insaturação de anéis) deverá ter dependido de várias molibdo- e tungstoenzimas. Um exemplo notável deste passado longínquo está no catabolismo actual das purinas (xantina). A dependência em molibdénio deste processo é comum a todas as formas de vida, conhecendo-se apenas um pequeno número de organismos que usam outros mecanismos para oxidarem a xantina (é o caso de algumas leveduras (secção 5)). Esta quase ubiquidade da utilização do molibdénio reconfirma o papel crucial que este elemento desempenha na vida na Terra.

A capacidade de manipular aldeídos/carboxilatos e compostos heterocíclicos é muito importante para os organismos superiores. Nas plantas, a produção de ácido abscísico, uma hormona envolvida no desenvolvimento e na resposta a várias situações de stresse abiótico e biótico, é catalisada por uma $\mathrm{AO}$ a partir do respetivo aldeído; a AO de plantas está igualmente envolvida na biossíntese da auxina ácido indole-3-acético [61,62]. Nos mamíferos, a AO participa no metabolismo de neurotransmissores e na formação de ácido retinóico, um metabolito do retinol (vitamina A) que está envolvido no desenvolvimento e crescimento [63].
Devido à sua capacidade de metabolizar compostos heterocíclicos, tanto a AO, como a XO e a mARC desempenham papeis relevantes do metabolismo de compostos xenobióticos dos organismos superiores. Além dos substratos "clássicos" mencionados (acima e Quadro 1), a XO e a AO catalisam também oxidações (maioritariamente hidroxilações) em átomos de carbono de uma vasta gama de compostos heterocíclicos aromáticos, nomeadamente, derivados de pirimidinas, purinas, pteridinas e compostos relacionados, e ainda de compostos contendo grupos aldeído; a XO e a AO usam igualmente diferentes substratos oxidantes, catalisando a redução de vários $S$-óxidos, $N$-óxidos e outros compostos [64-66]. Por seu lado, a mARC catalisa a redução (de-hidroxilação) de uma ampla variedade de compostos $N$-hidroxilados (eq. 12 no Quadro 1) [67,68]. Esta "promiscuidade" - não usual em enzimas, as quais aprendemos serem específicas - faz com que estas três enzimas desempenhem um papel fundamental na defesa dos organismos contra a exposição/ ingestão de compostos xenobióticos [63,69,70]. No caso dos humanos, esta linha de defesa pode, porém, comprometer o desenvolvimento de novos compostos com fins terapêuticos, como discutido na "Caixa 3 - Molibdénio na saúde humana".

Como salientado acima, o molibdénio é também essencial no catabolismo das purinas em animais e plantas, onde a XO é responsável pela hidroxilação sequencial da hipoxantina a xantina e desta a urato (eq. 2 no Quadro 1). Ao contrário do metabolismo discutido acima, onde o molibdénio é apresentado como desempenhando apenas um papel fisiológico, neste caso do catabolismo das purinas, o molibdénio tem um lado "obscuro" conhecido de muitos: é responsável pela produção de urato, o qual, em concentrações elevadas, constitui um fator de risco para a saúde humana. Por este motivo, uma das estratégias terapêuticas contra a hiperuricemia passa pela inibição da XO, como discutido na Caixa 3.

O molibdénio está também intimamente relacionado com vias de sinalização celular em condições de normoxia, através da geração de espécies reativas de oxigénio (ROS), nomeadamente o peróxido de hidrogénio (eq. 2 e 3 no Quadro 1) [13,14]. Esta atividade está na base de outra ligação do molibdénio à saúde humana: envolvimento em doenças mediadas por ROS, as quais se postulam ocorrer quando a produção de ROS fica desregulada e/ou é excessiva e ultrapassa os mecanismos de defesa antioxidante. Têm sido sugeridos vários mecanismos de doença mediados por ROS e molibdoenzimas, em particular na lesão de isquemia e noutras doenças cardiovasculares [71-85], as quais constituem uma das principais preocupações da nossa Sociedade ocidental. A capacidade da XO e AO para gerarem NO em condições de hipóxia (como descrito acima; eq. 26) define outra ligação do molibdénio à saúde humana e a doenças associadas a uma reduzida bioatividade do NO, como a hipertensão e a disfunção endotelial [49-53].

A relevância do molibdénio para a vida na Terra está também patente no metabolismo de um outro elemento: o enxofre. A dependência em molibdénio do catabolismo de compostos de enxofre, na forma de enzimas que oxidam o sulfito (SOs e sulfito desidrogenases), é quase ubí- 
qua a todos os organismos vivos [86,87]. Nos humanos, a oxidação (remoção) do sulfito, o qual apresenta uma toxicidade elevada, é absolutamente crucial para a nossa sobrevivência e constitui, por isso, o exemplo mais crítico da dependência em molibdénio dos humanos, como discutido na Caixa 3. As enzimas que oxidam o sulfito são ainda essenciais para os procariontes que oxidam compostos de enxofre em "cadeias respiratórias", como fonte de energia, como por exemplo Starkeya novella, Sinorhizobium meliloti ou Thermus thermophilus [86-90], estendendo-se, deste modo, o papel do molibdénio ao ciclo do enxofre.

\section{A vida sem molibdénio}

A presença de molibdoenzimas nos três domínios da vida ilustra bem a universalidade da utilização de molibdénio. Porém, existem algumas exceções relevantes em procariontes e em alguns ramos do reino Fungi, incluindo Saccharomycotina, Schizosaccharomycetes e Microsporidia, e do reino Protista, Kinetoplastidas tais como Leishmania e Trypanosoma [91-94]. A maioria dos organismos que não usam molibdénio vivem em associação com um hospedeiro, como é o caso de vários simbiontes intracelulares obrigatórios, bactérias e parasitas. Este estilo de vida sugere que estes organismos usam as vias dependentes de molibdénio do hospedeiro ou que os seus habitats conduziram à perda de utilização do molibdénio devido ao espaço e/ou recursos limitados.

Diferentes fatores terão contribuído, certamente, para que estes organismos "exceção" tenham perdido a capacidade de utilizar o molibdénio no decurso da evolução da vida. Mas é notável que, ao contrário da utilização de cobre e selénio, esses fatores não estejam relacionados com a utilização de oxigénio ou de o habitat ser terrestre versus aquático [94].

\section{A vida com tungsténio}

O tungsténio foi, provavelmente, um elemento essencial para as formas de vida primitivas. A sua maior biodisponibilidade na Terra primitiva, relativamente ao molibdénio, sugere que o tungsténio terá desempenhado o papel que as molibdoenzimas contemporâneos desempenham atualmente, como discutido na secção 2. Presentemente, porém, apenas um número limitado de organismos usa o tungsténio e, tanto quanto se sabe, a sua utilização não é crítica para a vida na Terra. Contudo, o tungsténio é essencial para vários organismos, na sua maioria anaérobios termófilos, embora também esteja presente em bactérias aeróbias e mesófilas [16,17]. Devido às especificidades destes organismos, o metabolismo dependente de tungsténio é muito menos conhecido, mas é responsável pela interconversão reversível entre aldeídos e carboxilatos, dióxido de carbono e formato e também pela metabolização de compostos heterocíclicos, tal como discutido em paralelo com o molibdénio, na secção 4.

\section{Perspetivas}

Foi surpreendente quando, já na segunda metade do século XX, se reconheceu que o molibdénio e o tungsténio eram usados pelos organismos vivos. Até então, não se pensava que estes dois elementos "pesados" pudessem desempenhar um papel biológico, muito menos se poderia imaginar que o molibdénio fosse essencial para os humanos. Presentemente, conhecem-se quase uma centena de enzimas que usam estes metais nos seus centros ativos para catalisarem reações redox. O tungsténio é, tanto quanto se sabe, usado apenas por procariontes e em habitats específicos. O molibdénio, pelo contrário, é essencial a todas as formas de vida, desempenhando um papel crítico na fixação do dinitrogénio atmosférico. A vida e a Terra seriam, certamente, muito diferentes sem o molibdénio!

Caixa 1 - Ambiente e alimentação: um problema global onde o molibdénio desempenha um papel crítico

O crescimento exponencial da população humana e a consequente necessidade de alimentos tem levado a um aumento global da agricultura intensiva, com o uso massivo de fertilizantes de nitrogénio (e não só) [95]. A sobrecarga dos solos com nitrato e amónio contamina não só os próprios solos, terras e rochas, mas também as linhas de água doce aéreas e subterrâneas e as águas marinhas, causando uma cascata de problemas ambientais e de saúde humana. O nitrato, muito solúvel, polui os aquíferos que fornecem a água para consumo humano e contamina toda a cadeia alimentar, culminado no peixe que consumimos. Juntamente com os compostos de fósforo (também presentes nos fertilizantes), é responsável pelos fenómenos, cada vez mais frequentes, de eutrofização dos ecossistemas aquáticos e sua concomitante destruição [96]. Acresce ainda que, a elevada solubilidade destes compostos faz com que sejam transportados ao longo de grandes distâncias, levando os problemas ambientais e de saúde humana para locais muito distantes dos da sua origem. Neste contexto, é urgente implementar medidas de redução do uso de fertilizantes e soluções para mitigar a atual contaminação por nitrato. A introdução de etapas de remoção do nitrato nas estações de tratamento de águas é uma estratégia já implementada em vários locais, recorrendo ao uso de organismos capazes de o metabolizarem e/ou de converterem, por exemplo, em dinitrogénio inerte (Figura 7) [41-45]. Aqui, o papel das molibdoenzimas responsáveis pela redução do nitrato (NaRs) é crucial.

Uma outra dimensão deste problema que é necessário repensar diz respeito à produção dos fertilizantes. Na nossa Sociedade moderna, o fator que mais frequentemente limita a produção agrícola é a biodisponibilidade de nitrogénio nos solos. A dimensão deste problema é evidenciada nos estudos que mostram que aproximadamente metade da população humana não existiria (pois não poderia ser alimentada) sem o recurso aos fertilizantes produzidos industrialmente [42]. A produção industrial de amoníaco é feita através do processo de Haber-Bosch, um processo de catálise heterogénea que opera a temperaturas e pressões muito elevadas para reduzir o dinitrogénio gasoso a amoníaco [97,98]. Este processo industrial não é energeticamente eficiente, nem ambientalmente responsável. A sua ineficiência é ainda mais percetível quando se compara com o processo biológico "suave", levado a cabo pela nitrogenase (eq. 1 no Quadro 1) 
à temperatura e pressão ambientes e a valores de pH próximos de 7. A consciencialização dos problemas ambientais associados à necessidade de "alimentar o mundo" tem motivado inúmeros esforços para melhor compreender a redução biológica do nitrogénio (conhecida desde meados do século XIX [99]). O conhecimento adquirido deverá levar ao desenvolvimento de um catalisador mais eficiente e mais "verde" (amigo do ambiente); poderá também levar ao desenvolvimento de organismos geneticamente modificados, capazes de produzirem o "seu" nitrogénio (ainda que esta solução seja ecologicamente questionável).

Caixa 2 - A pegada de carbono e a reutilização do dióxido de carbono atmosférico na produção de combustíveis e outros compostos de valor acrescentado

A necessidade global de energia e a nossa atual dependência de combustíveis fósseis causou (causa e continuará a causar nos próximos anos) o aumento do dióxido de carbono na atmosfera para os valores mais elevados desde que os registos começaram [100]. Devido ao seu significativo efeito de estufa, o aumento do dióxido de carbono é responsável por enormes e imprevisíveis impactos no clima da Terra, além de ser responsável pelo aquecimento e acidificação dos oceanos (o seu maior reservatório) [101,102]. Embora alguns autores defendam que estas alterações já não são reversíveis, todos estão de acordo que as emissões de dióxido de carbono têm de ser drasticamente reduzidas, que as fontes de energia do futuro (breve) têm de ser "neutras em carbono" e baseadas em energia solar, eólica ou geotermal e que novos métodos de armazenamento, transporte e utilização da energia obtida destas fontes têm ser desenvolvidos rapidamente. É igualmente unânime que o dióxido de carbono existente, pela sua abundância, é um recurso atrativo para a produção de "combustíveis" e outros compostos de valor acrescentado. Existe, por isso, um enorme interesse em desenvolver estratégias para eficientemente captar e utilizar o dióxido de carbono atmosférico, usando, claro, fontes de energia renováveis, de "carbono zero" [100,103-106]. Um dos principais desafios neste objetivo é a estabilidade cinética e termodinâmica da molécula de dióxido de carbono que tornam a sua ativação em laboratório, ou industrial, uma tarefa difícil. Porém, os organismos vivos encontraram (desenvolveram) várias estratégias para ativarem e usarem o dióxido de carbono em seu proveito, usando diferentes abordagens químicas, em enzimas específicas, para hidrolisarem a ligação C-O e formarem ligações C-C e C-H (por exemplo, na redução a monóxido de carbono, adição a 1,5-bisfosfato de ribulose e redução a formato, respetivamente) [100,107-113]. Certamente que o conhecimento da estratégia química usada pelos organismos vivos deverá levar ao desenvolvimento de novos (bio)catalisadores para uma utilização eficiente do dióxido de carbono. Neste contexto, o estudo de FDHs, dependentes de molibdénio e tungsténio (eq. 17 e 20), ou de materiais miméticos dos seus centros ativos é muito promissor [32-35,58]. O uso de enzimas conferirá ao biocatalisador especificidade, seletividade e eficiência: formar-se-á apenas formato (não sendo necessários processos de purificação adicionais) e a reação procederá em condições "suaves", de temperatura e pressão ambiente e a valores de pH próximos de 7. Por outro lado, a formação de formato é igualmente muito interessante por diferentes motivos: (i) é o primeiro intermediário estável na redução do dióxido de carbono a metanol ou metano, (ii) é usado como ponto de partida ("building block") em várias indústrias químicas, (iii) é uma fonte viável de energia, mais fácil de armazenar e transportar do que o di-hidrogénio (e ambos são oxidados a potenciais semelhantes) e (iv) diferentes "fuel cells" que usam formato estão já a ser desenvolvidas. Todas estas vantagens têm motivado um grande interesse no estudo das FDHs com vista ao desenvolvimento de (bio)catalisadores mais eficientes e "verdes" para a utilização do dióxido de carbono atmosférico.

Caixa 3 - Molibdénio na saúde humana

O molibdénio desempenha vários papéis fisiológicos cruciais nos humanos, um facto notável quando se faz notar que possuímos apenas quatro molibdoenzimas, $\mathrm{XO}, \mathrm{AO}$, SO e mARC.

Um dos processos metabólicos dependentes de molibdénio é o catabolismo das purinas (um processo cuja dependência em molibdénio é quase universal (secção 4)). Neste, a XO é responsável por catalisar a hidroxilação sequencial de hipoxantina a urato (eq. 2 no Quadro 1), o qual, nos humanos, é o produto terminal do catabolismo das purinas [114,115] (em alguns animais, o urato é ainda oxidado a alantoína, pela uricase). Uma concentração elevada de urato no sangue é um fator de risco para desenvolvimento de gota (condição causada pela deposição de cristais de ácido úrico nas articulações, tendões e tecidos envolventes) [116], doença renal [117], disfunção endotelial e outras doenças relacionadas com síndromes metabólicos [118-122]. Para controlar a concentração de urato, os clínicos podem recorrer a diferentes estratégias, entre as quais aumentar a sua excreção e/ou diminuir a sua formação, através da inibição da XO [123]. Por este motivo, a XO humana é um dos alvos das terapias contra a hiperuricemia e a gota. A eficácia da inibição da XO como estratégia terapêutica contra a gota está atualmente bem estabelecida e o inibidor alopurinol (um isómero da hipoxantina) é usado com sucesso em clínica há mais de 40 anos. Presentemente, há um grande interesse na identificação de novos inibidores da XO, que não interfiram com outras vias metabólicas, e alguns compostos encontram-se já em diferentes fases do processo de desenvolvimento de fármacos.

O papel que as molibdoenzimas desempenham no metabolismo de xenobióticos, devido à sua "promiscuidade" para substratos (secção 4), tem atraído igualmente a atenção da indústria farmacêutica [69,70]. A importância toxicoló- 
gica e farmacológica destas enzimas pode ser constatada, por exemplo, (i) na ativação nociva de azocompostos usados como corantes em alimentos e cosméticos [124] (conversão em compostos nocivos), (ii) na ativação benéfica de fármacos antineoplásicos [125,126] e anti-hipertensivos [127] (formação dos compostos bioativos), (iii) assim como na "desativação" de vários outros fármacos (conversão de compostos bioativos em compostos sem atividade biológica ou mesmo tóxicos) [63,70,128-135]. De facto, a "promiscuidade" da XO, AO e mARC tem causado problemas sérios ao desenvolvimento de novos fármacos, pois compostos desenhados para resistirem às enzimas hepáticas (nomeadamente ao sistema de isoenzimas dependente do citocromo $\mathrm{P}_{450}$ ) são muitas vezes oxidados/reduzidos pelas molibdoenzimas. Esta metabolização pelas molibdoenzimas reduz a biodisponibilidade do fármaco ativo e, consequentemente, diminui/elimina a sua eficácia terapêutica, fazendo com que muitos ensaios clínicos falhem. De modo a contrariar estes insucessos (que acarretam perdas financeiras elevadas para a indústria farmacêutica), as propriedades catalíticas das molibdoenzimas estão a ser estudadas intensivamente, o que tem despertado um interesse renovado nestas enzimas.

Da discussão acima e da secção 4, é claro o impacto que as molibdoenzimas têm no metabolismo humano. Porém, o papel mais impressionante deste metal é através da enzima SO, cuja deficiência constitui um risco de vida real [136140]. O sulfito (derivado não apenas do catabolismo dos aminoácidos contendo enxofre, mas também de compostos xenobióticos sulfurados) é muito tóxico para as células e a sua oxidação a sulfato, catalisada pela SO (eq. 8 no Quadro 1) é crítica para a sobrevivência da célula e do indivíduo. Este papel vital é bem demonstrado pelos problemas neurológicos neonatais severos causados por deficiências na SO, os quais incluem crescimento cerebral atenuado, alterações cognitivas severas, convulsões e morte prematura. A deficiência na SO pode ser causada por incapacidade de biossintetizar o cofator de piranopterina (Figura 3) ou por mutação(ões) na proteína. No primeiro caso, a deficiência em SO pode ser tratada com a administração contínua do cofator produzido sinteticamente, o que constitui a única esperança de vida para os indivíduos que nascem com esta condição.

\section{Agradecimentos}

Este trabalho foi financiado pelo Laboratório Associado para a Química Verde - LAQV, financiado por fundos nacionais através da Fundação para a Ciência e a Tecnologia, MCTES (UID/QUI/50006/2019). LBM agradece igualmente à Fundação para a Ciência e a Tecnologia, MCTES, pelo Programa CEEC-Individual 2017. Os autores agradecem à Doutora Patricia Marta e ao Professor Nuno Leal (FCT NOVA) pelas imagens e informação sobre os minerais.

\section{Referências}

[1] M. E. Weeks, J. Chem. Edu. 32 (1932) 459-473.

[2] The University of Sheffield WebElements webpage: http:// www.webelements.com

[3] The Royal Society Periodic Table webpage: http://www.rsc. org/periodic-table

[4] P.A.O.S. Marta, Tese de Doutoramento, "A Coleção Nacional de Mineralogia do Museu Geológico num sistema de informação para o ensino e divulgação das Ciências da Terra", Faculdade de Ciências e Tecnologia, Universidade Nova de Lisboa, 2018.

[5] D.A. Richert, W.W. Westerfeld, J. Biol. Chem. 203 (1953) 915-923.

[6] D.J. Nicholas, A. Nason, J. Biol. Chem. 207 (1954) 353-360.

[7] L. Maia, I. Moura, J.J.G. Moura, EPR spectroscopy on mononuclear molybdenum-containing enzymes, in G. Hanson, L.J. Berliner (ed.) "Future directions in metalloprotein and metalloenzyme research", Biological Magnetic Resonance, vol. 33, Springer International Publishing, Cham, 1017, 55101.

[8] I. Yamamoto, T. Saiki, S.M. Liu, L.G. Ljungdahl, J. Biol. Chem. 258 (1983) 1826-1832.

[9] G.N. George, R.C. Prince, S. Mukund, M.W.W. Adams, J. Am. Chem. Soc. 114 (1992) 3521-3523.

[10] M.K. Chan, S. Mukund, A. Kletzin, M.W.W. Adams, D.C. Rees, Science 267 (1995) 1463-1469.
[11] M.J. Romao, M. Archer, I. Moura, J.J.G. Moura, J. LeGall, R. Engh, M. Schneider, P. Hof, R. Huber, Science 270 (1995) 1170-1176.

[12] H. Schindelin, C. Kisker, J. Hilton, K.V. Rajagopalan, D.C. Rees, Science 272 (1996) 1615-1621.

[13] R. Hille, J. Hall, P. Basu, Chem. Rev. 114 (2014) 3963-4038.

[14] L. Maia, J.J.G. Moura, Molybdenum and tungsten-containing enzymes: an overview, in R. Hille, C. Schulzke, M. Kirk (ed.) "Molybdenum and tungsten enzymes: biochemistry", RSC Metallobiology Series No. 5, The Royal Society of Chemistry, Cambridge, 2017, 1-80.

[15] A. Havemeyer, F. Bittner, S. Wollers, R. Mendel, T. Kunze, B. Clement, J. Biol. Chem. 281 (2006) 34796-34802.

[16] M.K. Johnson, D.C. Rees, M.W.W. Adams, Chem. Rev. 96 (1996) 2817-2839.

[17] Hagen, W.R., Tungsten-containing enzymes, in R. Hille, C. Schulzke, M. Kirk (ed.) "Molybdenum and tungsten enzymes: biochemistry", RSC Metallobiology Series No. 5, The Royal Society of Chemistry, Cambridge, 2017, 313342.

[18] Y. Hu, M.W. Ribbe, J. Biol. Inorg. Chem. 20 (2015) 435445.

[19] L.C. Seefeldt, D.R. Dean, B.M. Hoffman, Nitrogenase mechanism: electron and proton accumulation and $\mathrm{N}_{2}$ reduction, in R. Hille, C. Schulzke, M. Kirk (ed.) "Molybdenum and tungsten enzymes: biochemistry", RSC Metallobiology Series No. 5, The Royal Society of Chemistry, Cambridge, 2017, 274-296.

[20] L.C. Seefeldt, J.W. Peters, D.N. Beratan, B. Bothner, S.D. Minteer, S. Raugei, B.M. Hoffman, Curr. Opin. Chem. Biol. 47 (2018) 54-59.

[21] R. Hille, Chem. Rev. 96 (1996) 2757-2816.

[22] K. Kishida, Y. Sohrin, K. Okamura, J. Ishibashi, Earth Planet. Sci. Lett. 222 (2004) 819-833.

[23] J.J.R. Fraústo da Silva, R.J.P. Williams, "The biological chemistry of the elements, the inorganic chemistry of life", Oxford University Press, Oxford, 2001.

[24] J. Wiegel, M.W.W. Adams, "Thermophiles: the keys to mo- 
lecular evolution and the origin of life", Taylor and Francis, London, 1998.

[25] B. Schoepp-Cothenet, R. Lis, P. Philippot, A. Magalon, A. Russell, W. Nitschke, Sci. Rep. 2 (2012) 263.

[26] C.D. Garner, L.J., Met. Ions Biol. Syst. 39 (2002) 699-726.

[27] Y.M. Heimer, J.L. Wray, P. Filner, Plant Physiol. 44 (1969) 1197-9119.

[28] A.M. Sevcenco, L.E. Bevers, M.W.H. Pinkse, G.C. Krijger, H.T. Wolterbeek, P.D.E.M. Verhaert, W.R. Hagen, P.L. Hagedoorn, J. Bacteriol. 192 (2010) 4143-4152.

[29] S.J.N. Burgmayer, E.I. Stiefel, J. Chem. Educ. 62 (1985) 943-953.

[30] E.E. Harlan, J.M. Berg, R.H. Holm, J. Am. Chem. Soc. 108 (1986) 6992-7000.

[31] R.H. Holm, J.P. Donahue, Polyhedron 12 (1993) 571-575.

[32] D. Niks, J. Duvvuru, M. Escalona, R. Hille, J. Biol. Chem. 291 (2016) 1162-1174.

[33] L. Maia, L. Fonseca, I. Moura, J.J.G. Moura, J. Am. Chem. Soc. 138 (2016) 8834-8846.

[34] G. Dong, U. Ryde, J. Biol. Inorg. Chem. 23 (2018) 12431254.

[35] D. Niks, R. Hille, Protein Sci. 28 (2019) 111-122.

[36] K.G. Matz, R.P. Mtei, B. Leung, S.J.N. Burgmayer, M.L. Kirk, J. Am. Chem. Soc. 132 (2010) 7830-7831.

[37] C. Dong, J. Yang, S. Leimkühler, M.L. Kirk, Inorg. Chem. 53 (2014) 7077-7079.

[38] R.A. Rothery, J.H. Weiner, J. Biol. Inorg. Chem. 20 (2015) 349-372.

[39] R.A. Rothery, B. Stein, M. Solomonson, M.L. Kirk, J.H. Weiner, Proc. Natl. Acad. Sci. U. S. A. 109 (2012) 1477314778.

[40] P. Basu, S.N.J. Burgmayer, Coord. Chem. Rev. 255 (2011) 1016-1038.

[41] L.B. Maia, J.J.G. Moura, Chem. Rev. 114 (2014) 5273-5357.

[42] D.E. Canfield, A.N. Glazer, P.G. Falkowski, Science 330 (2010) 192-196.

[43] I. Moura, L. Maia, S.R. Pauleta, J.J.G. Moura, A bird's-eye view of denitrification in relation to the nitrogen cycle, in I. Moura, J.J.G. Moura, J.J.G., S.R. Pauleta, L. Maia (ed.) "Metalloenzymes in denitrification: applications and environmental impacts", RSC Metallobiology Series No. 9, The Royal Society of Chemistry, Cambridge, 2017, 1-10.

[44] M.M. Kuypers, H. K. Marchant, B. Kartal, Nat. Rev. Microbiol. 16 (2018) 263.

[45] N. Lehnert, H.T. Dong, J.B. Harland, A.P. Hunt, C.J. White, Nat. Rev. Chem. 2 (2018) 278-289.

[46] A.D. Anbar, A. H. Knoll, Science 297 (2002) 1137-1142.

[47] C. Scott, T.W. Lyons, A. Bekker, Y. Shen, S.W. Poulton, X. Chu, A.D. Anbar, Nature 452 (2008) 456-460.

[48] J.B. Glass, F. Wolfe-Simon, A.D. Anbar, Geobiology 7 (2009) 100-123.

[49] E.A. Jansson, L. Huang, R. Malkey, M. Govoni, C. Nihlen, A. Olsson, Nat. Chem. Biol. 4 (2008) 411-417.

[50] J. O. Lundberg, et al., Nat. Chem. Biol. 5 (2009) 865-869.

[51] L. Maia, J.J.G. Moura, J. Biol. Inorg. Chem. 20 (2015) 403 433.

[52] L. Maia, J.J.G. Moura, Redox Biol. 19 (2018) 274-289.

[53] A. W. DeMartino, D. B. Kim-Shapiro, R.P. Patel, M.T. Gladwin, Br. J. Pharmacol. 176 (2019) 228-224.

[54] M. Tejada-Jimenez, A. Llamas, A. Galván, E. Fernández, Plants 8 (2019) 56
[55] N.J. Gilberthorpe, R.K. Poole, J. Biol. Chem. 283 (2008) 11146-11154.

[56] C.E. Vine, S.K. Purewal, J.A. Cole, FEMS Microbiol. Lett. 325 (2011) 108-114.

[57] L. Maia, J.J.G. Moura, I. Moura, J. Biol. Inorg. Chem. 20 (2015) 287-309.

[58] L. Maia, I. Moura, J.J.G. Moura, Inorg. Chim. Acta 455 (2017) 350-363.

[59] R.Hille, S. Dingwall, J. Wilcoxen, J. Biol. Inorg. Chem. 20 (2015) 243-251.

[60] R.J.P. Williams, J.J.R. Fraúto da Silva, J.J.R., Biochem. Biophys. Res. Commun. 292 (2002) 293-299.

[61] M. Seo, H. Koiwai, S. Akaba, T. Komano, T. Oritani, Y. Kamiya, T. Koshiba, Plant J. 23 (2000) 481-488.

[62] M. Seo, A.J. Peeters, H. Koiwai, T. Oritani, A. Marion-Poll, J.A. Zeevaart, M. Koornneef, Y. Kamiya, T. Koshiba, Proc. Natl. Acad. Sci. U.S.A. 97 (2000) 12908-12913.

[63] E. Garattini, M. Fratelli, M. Terao, Cell Mol. Life Sci. 65 (2008) 1019-1048.

[64] K.N. Murray, S. Chaykin, J. Biol. Chem. 241 (1966) 34683473.

[65] T.A. Krenitsky, S.M. Neil, G.B. Elion, G.H. Hitchings, Arch. Biochem. Biophys. 150 (1972) 585-593.

[66] W.W. Hall, T.A. Krenitsky, Arch. Biochem. Biophys. 251 (1986) 36-51.

[67] A. Havemeyer, J. Lang, B. Clement, Drug Metab. Rev. 43 (2011) 524-539.

[68] O. Gudrun Ott, A. Havemeyer, B. Clement, J. Biol. Inorg. Chem. 20 (2015) 265-275.

[69] T.A. Krenitsky, Biochem. Pharmacol. 27 (1978) 2763-2764.

[70] C. Mota, C. Coelho, S. Leimkühler, E. Garattini, M. Terao, T. Santos-Silva, M.J. Romão, Coord. Chem. Rev. 368 (2018) 35-59.

[71] D.N. Granger, G. Rutili, J.M. McCord, Gastroenterology 81 (1981) 22-29.

[72] J.M. McCord, N. Engl. J. Med. 312 (1985) 159-163.

[73] J.L. Zweier, R. Broderick, P. Kuppusamy, S. Thompson-Gorman, G.A. Lutty, J. Biol. Chem. 269 (1994) 24156-24162.

[74] L. Mira, L. Maia, L. Barreira, C.F. Manso, Arch. Biochem. Biophys. 318 (1995) 53-58.

[75] T. Nishino, S. Nakanishi, K. Okamoto, J. Mizushima, H. Hori, T. Iwasaki, T. Nishino, K. Ichimori, H. Nakazawa, Biochem. Soc. Trans. 25 (1997) 783-786.

[76] R.M. Wright, J.E. Repine, Biochem. Soc. Trans. 25 (1997) 799-804.

[77] K.B. Beckman, B.N. Ames, Physiol. Rev. 78 (1998), 547581.

[78] H. Suzuki, F.A. Delano, D.A. Parks, N. Jamshidi, D.N. Granger, H. Ishii, M. Suematsu, B. Zweifach, G.W. SchmidSchonbein, Proc. Natl. Acad. Sci. U.S.A. 95 (1998) 4754 4759.

[79] R. Harrison, Free Radical Biol. Med. 33 (2002) 774-797.

[80] F. Stirpe, M. Ravaioli, M. Battelli, S. Musiani, G.L. Grazi, Am. J. Gastroenterol. 97 (2002) 2079-2085.

[81] D. Wu, A.I. Cederbaum, Alcohol Res. Health 27 (2003) $277-$ 284.

[82] C.E. Berry, J.M. Hare, J. Physiol. 555 (2004) 589-606.

[83] D.M. Small, J.S. Coombes, N. Bennett, D.W. Johnson, G.C. Gobe, Nephrology 17 (2012) 311-321.

[84] M.M. Bachschmid, S. Schildknecht, R. Matsui, R. Zee, D. Haeussler, R.A. Cohen, D. Pimental, B. Loo, Ann. Med. 45 
(2013) 17-36.

[85] N.R. Madamanchi, M.S. Runge, Free Radical Biol. Med. 61 (2013) 473-501.

[86] U. Kappler, J. H. Enemark, J. Biol. Inorg. Chem. 20 (2015) 253-264.

[87] Kappler, U., Schwarz, G., The sulfite oxidase family of molybdenum enzymes, in R. Hille, C. Schulzke, M. Kirk (ed.) "Molybdenum and tungsten enzymes: biochemistry", RSC Metallobiology Series No. 5, The Royal Society of Chemistry, Cambridge, 2017, 240-273.

[88] U. Kappler, B. Bennett, J. Rethmeier, G. Schwarz, R. Deutzmann, A.G. McEwan, C. Dahl, J. Biol. Chem. 275 (2000) 13202-13212.

[89] A. Di Salle, G. D’Errico, F. La Cara, R. Cannio, M. Rossi, Extremophiles 10 (2006) 587-598.

[90] J.J. Wilson, U. Kappler, Biochim. Biophys. Acta 1787 (2009) 1516-1525.

[91] Y. Zhang, V.N. Gladyshev, J. Mol. Biol. 379 (2008) 881-899.

[92] Y. Zhang, V.N. Gladyshev, J. Biol. Chem. 285 (2010) 3393 3405.

[93] Y. Zhang, S. Rump, V.N. Gladyshev, Coord. Chem. Rev. 255 (2011) 1206-1217.

[94] V.N. Gladyshev, Y. Zhang, Abundance, ubiquity and evolution of molybdoenzymes, in R. Hille, C. Schulzke, M. Kirk (ed.) "Molybdenum and tungsten enzymes: biochemistry", RSC Metallobiology Series No. 5, The Royal Society of Chemistry, Cambridge, 2017, 81-99.

[95] J.N. Galloway, A.R. Townsend, M. Nekunda, Z. Cai, J.R. Freney, L.A. Martinelli, S.P. Seitzinger, M.A. Sutton, Science 320 (2008) 889-892.

[96] J.A. Camrgo, Environ. Int. 32 (2006) 831-848.

[97] F. Haber, Naturwissenschaften 11 (1923) 339-342.

[98] R. Schlögl, Angew. Chem. Int. Ed. 42 (2003) 2004-2008.

[99] C.C. Jodin, R. Acad. Paris 55 (1862) 612.

[100] A.M. Appel, J.E. Bercaw, A.B. Bocarsly, H. Dobbek, D.L. DuBois, M. Dupuis, J.G. Ferry, E. Fujita, R. Hille, J.J. Kenis, C.A. Kerfeld, R.H. Morris, C.H. Peden, A.R. Portis, S.W. Ragsdale, T.B. Rauchfuss, J.N. Reek, L.C. Seefeldt, R.K. Thauer, G.L. Waldrop, Chem. Rev. 113 (2013) 6621-6658.

[101] S.C. Doney, V.J. Fabry, R.A. Feely, J.A. Kleypas, Annu. Rev. Mar. Sci. 1 (2009) 169-192.

[102] P. Friedlingstein, R.M. Andrew, J. Rogelj, G.P. Peters, J.G. Canadell, R. Knutti, G. Luderer, M.R. Raupach, M. Schaeffer, D.P. van Vuuren, C. Le Quéré, Nat. Geosci. 7 (2014) 709-713.

[103] D.M. D’Alessandro, B. Smit, J.R. Long, Angew. Chem. Int. Ed. 49 (2010) 6058-6082.

[104] J. Langanke, A. Wolf, J. Hofmann, K. Bohm, M.A. Subhani, T.E. Muller, W. Leitner, C. Gurtler, Green Chem. 16 (2014) 1865-1879.

[105] S. Saeidi, N.A.S. Amin, M.R. Rahimpour, J. CO2 Util. 5 (2014) 66-75.

[106] R.F. Service, Science 349 (2015) 1158-1160.

[107] E.E. Benson, C.P. Kubiak, A.J. Sathrum, J.M. Smieja, Chem. Soc. Rev. 38 (2009) 89-99.

[108] S.M. Glueck, S. Gumus, W.M.F. Fabian, K. Faber, Chem. Soc. Rev. 39 (2009) 313-328.

[109] C. Federsel, R. Jackstell, M. Beller, Angew. Chem. Int. Ed. 49 (2010) 6254-6247.

[110] B. Kumar, M. Llorente, J. Froehlich, T. Dang, A. Sathrum, C.P. Kubiak, Annu. Rev. Phys. Chem. 63 (2012) 541-569.
[111] C. Costentin, M. Robert, J.M. Saveant, Chem. Soc. Rev. 42 (2013) 2423-2436.

[112] A. Alissandratos, C.J. Easton, Beilstein J. Org. Chem. 11 (2015) 2370-2387.

[113] B. Mondal, J. Song, F. Neese, S. Ye, Curr. Opin. Chem. Biol. 25 (2015) 103-109.

[114] M. Ichikawa, T. Nishino, T. Nishino, A. Ichikawa, J. Histochem. Cytochem. 40 (1992) 1097-1103.

[115] T. Nishino, K. Okamoto, J. Biol. Inorg. Chem. 20 (2015) 195-207.

[116] J.E. Seegmiller, Arthritis Rheum. 8 (1965) 714-725.

[117] R.P. Obermayr, C. Temml, G. Gutjahr, M. Knechtelsdorfer, R. Oberbauer, R. Klauser-Braun, J. Am. Soc. Nephrol. 19 (2008) 2407-2413.

[118] J. Kanellis, D.H. Kang, Semin. Nephrol. 25 (2005) 39-42.

[119] U.M. Khosla, S. Zharikov, J.L. Finch, T. Nakagawa, C. Roncal, W. Mu, K. Krotova, E.R. Block, S. Prabhakar, R.J. Johnson, Kidney Int. 67 (2005) 1739-1742.

[120] F. Perticone, R. Maio, J.E. Tassone, M. Perticone, A. Pascale, A. Sciacqua, G. Sesti, Int. J. Cardiol. 167 (2013) 232-236.

[121] D. Grassi, G. Desideri, C. Ferri, Curr. Pharm. Des. 20 (2014) 6089-6095.

[122] H. K. Choi, E.S. Ford, C. Li, G. Curhan, Arthritis Rheum. 57 (2007) 109-115.

[123] D. Khanna, et al., Arthritis Care Res. 64 (2012) 1431-1446.

[124] A.M. Stoddart, W.G. Levine, Biochem. Pharmacol. 43 (1992) 2227-2235.

[125] G. Fabre, R. Seither, D. Goldman, Biochem. Pharmacol. 35 (1986) 1325-1330.

[126] S.B. Yee, C.A. Pritsos, Arch. Biochem. Biophys. 347 (1997) 235-241.

[127] M. Dambrova, S. Uhlen, C.J. Welch, J.E.S. Wikberg, Eur. J. Biochem. 257 (1998) 178-184.

[128] C. Beedham, Pharm. World Sci. 19 (1997) 255-263.

[129] S. Diamond, J. Boer, T.P. Maduskuie, N. Falahatpisheh, Y. Li, S. Yeleswaram, Drug Metab. Dispos. 38 (2010) 1277-1285.

[130] D.C. Pryde, D. Dalvie, Q. Hu, P. Jones, R.S. Obach, T.D. Tran, J. Med. Chem. 53 (2010) 8441-8460.

[131] E. Garattini, M. Terao, Drug Metab. Rev. 43 (2011) 374-386.

[132] T. Akabane, K. Tanaka, M. Irie, S. Terashita, T. Teramura, Xenobiotica 41 (2011) 372-384.

[133] X. Zhang, H.H. Liu, P. Weller, M. Zheng, W. Tao, J. Wang, G. Liao, M. Monshouwer, G. Peltz, Pharmacogenomics J. 11 (2011) 15-24.

[134] S. Sanoh, Y. Tayama, K. Sugihara, S. Kitamura, S. Ohta, Drug Metab. Pharmacokinet. 30 (2015) 52-63.

[135] R. Kumar, G. Joshi, H. Kler, S. Kalra, M. Kaur, R. Arya, Med. Res. Rev. 38 (2017) 1073-1125.

[136] K. Vijayakumar, R. Gunny, S. Grunewald, L. Carr, K.W. Chong, C. DeVile, R. Robinson, N. McSweeney, P. Prabhakar, Pediatr. Neurol. 45 (2001) 246-252.

[137] J.L. Johnson, Prenat. Diagn. 23 (2003) 6-8.

[138] J.O. Sass, A. Gunduz, C.A.R. Funayama, B. Korkmaz, K.G.D. Pinto, B. Tuysuz, L.Y. Santos, E. Taskiran, M.F. Turcato, C.W. Lam, J. Reiss, M. Walter, C. Yalcinkaya, J.S. Camelo, Brain Dev. 32 (2010) 544-549.

[139] N. Carmi-Nawi, G. Malinger, H. Mandel, K. Ichida, T. Lerman-Sagie, D. Lev, J. Child Neurol. 26 (2011) 460-464.

[140] G. Schwarz, A. Belaidi, Met. Ions Life Sci. 13 (2013) 415450. 